\title{
Fibroblast heterogeneity in the cancer wound
}

\author{
Daniel Öhlund, Ela Elyada, and David Tuveson
}

D. Öhlund, E. Elyada, and D. Tuveson are at the Cold Spring Harbor Laboratory, Cold Spring Harbor, NY 11724

\begin{abstract}
Fibroblasts regulate the structure and function of healthy tissues, participate transiently in tissue repair after acute inflammation, and assume an aberrant stimulatory role during chronic inflammatory states including cancer. Such cancer-associated fibroblasts (CAFs) modulate the tumor microenvironment and influence the behavior of neoplastic cells in either a tumor-promoting or tumor-inhibiting manner. These pleiotropic functions highlight the inherent plasticity of fibroblasts and may provide new avenues to understand and therapeutically intervene in malignancies. We discuss the emerging themes of CAF biology in the context of tumorigenesis and therapy.
\end{abstract}

\section{CORRESPONDENCE}

David Tuveson:

dtuveson@cshl.edu
Although the concept of "seed and soil" was proposed over 100 years ago (Paget, 1889), investigators have only recently revealed the fundamental importance of the tumor-associated stoma in cancer development. Fibroblasts are essential in tissue homeostasis and wound healing, and consistent with the hypothesis that "a tumor is a wound that never heals" (Dvorak, 1986), an emerging body of evidence demonstrates that the fibroblasts in tumors, often referred to as cancer-associated fibroblasts (CAFs), are key players in the process of tumorigenesis (Hanahan and Weinberg, 2011). Indeed, recent studies have shown that many of the cancer-promoting and therapyresisting properties of the stroma can be attributed to the activity of fibroblasts. It is necessary to acknowledge that CAFs can derive from multiple origins and make up a heterogeneous population of cells but nevertheless are united by their capacity to alter the tumor microenvironment and to change the fate of neoplastic cells.

To be able to fully understand the role of fibroblasts in cancer, it is important to consider the function of this cell type in normal tissues. Fibroblasts are elongated cells of mesodermal origin, showing a fusiform or spindle-like shape, and express fibroblast-specific protein 1 (FSP-1; Strutz et al., 1995). Beyond FSP-1, they show a complex expression pattern of protein markers, reflecting an inherent diversity within a population of fibroblasts (Anderberg and Pietras, 2009).

Fibroblasts are found embedded within the extracellular matrix (ECM) and are the most abundant cell type in connective tissue. The ECM is composed of fibrillar collagens, fibronectins, hyaluronic acid, and proteoglycans, providing a structural framework for all tissues. The ECM also acts as a reservoir for cytokines and growth factors, and as a scaffold for cell migration. In fact, fibroblasts are the major producers of the ECM and thereby participate in tissue homeostasis, and the regulation of interstitial fluid volume and pressure. Fibroblasts are also highly involved in regulating tissue remodeling and repair. Upon tissue damage, fibroblasts proliferate and differentiate into myofibroblasts, a process characterized by de novo expression of $\alpha$-smooth muscle actin $(\alpha-S M A)$, contractile stress fibers, and splice variants of fibronectin (Serini et al., 1998; Tomasek et al., 2002). The synthesis of ECM and ECM remodeling proteases is upregulated, resulting in deposition of a reactive stroma, often referred to as a desmoplastic reaction or desmoplastic stroma. The induced expression of $\alpha$-SMA alters cytoskeletal organization, which increases the contractile ability of myofibroblasts (Rønnov-Jessen and Petersen, 1996; Hinz et al., 2001). Myofibroblasts contract the ECM to bring the borders of the wound together, and secrete matrix proteins that repair the remaining tissue defects and attract epithelial cells to complete the healing process. Upon completion of wound healing, activated fibroblasts undergo apoptosis (Desmoulière et al., 1995) or a particular type of programmed cell death termed nemosis (programmed necrosis; Bizik et al., 2004).

\footnotetext{
2014 Öhlund et al. This article is distributed under the terms of an Attribution Noncommercial-Share Alike-No Mirror Sites license for the first six months after the publication date (see http://www.rupress.org/terms). After six months it is available under a Creative Commons License (Attribution-NoncommercialShare Alike 3.0 Unported license, as described at http://creativecommons.org/
} licenses/by-nc-sa/3.0/) 


\section{Definition and markers of CAFs}

CAFs are found in almost all solid tumors; however, their abundance varies between different types of cancers. For example, breast, prostate, and pancreatic cancers contain high numbers of CAFs, whereas brain, renal, and ovarian cancers demonstrate fewer (Neesse et al., 2011; Smith et al., 2013). They are defined as all the fibroblastic, nonneoplastic, nonvascular, nonepithelial, and noninflammatory cells found in a tumor (Fig. 1). However, there is no consensus on their molecular definition (Kalluri and Zeisberg, 2006; Orimo and Weinberg, 2007; Pietras and Ostman, 2010; Xing et al., 2010). CAFs can be distinguished from neoplastic cells that have undergone epithelial-mesenchymal transition and show a fibroblast-like morphology by their stable karyotype and the lack of genetic alterations. Although p53 mutations in CAFs have been reported (Kurose et al., 2002; Hill et al., 2005; Patocs et al., 2007), these studies have been criticized for using methods highly prone to generating experimental artifacts (Campbell et al., 2009). Moreover, recent studies have confirmed the lack of frequent mutations in CAFs (Qiu et al., 2008; Walter et al., 2008; Hosein et al., 2010).

The molecular definition of CAFs is still a debated issue, and emerging data demonstrate that CAFs make up a complex and heterogeneous population of cells. Several markers have been suggested in the past to define CAFs, but it is now being appreciated that these markers do not mark all CAFs and that most of them are not even unique to CAFs or to the fibroblasts lineage. $\alpha-\mathrm{SMA}$ is a robust CAF marker, which usually identifies CAFs with myofibroblast morphology (Desmoulière et al., 2004). Nonetheless, $\alpha$-SMA is also expressed by normal fibroblasts (Hawinkels et al., 2014), and in some cases, normal fibroblasts show comparable or even more $\alpha$-SMA expression compared with CAFs (Madar et al., 2009; Berdiel-Acer et al., 2014). $\alpha$-SMA expression is detected in other cell types as well, such as pericytes and smooth muscle cells surrounding vasculature, visceral smooth muscle cells, and cardiomyocytes (Wendling et al., 2009). The cell-surface serine

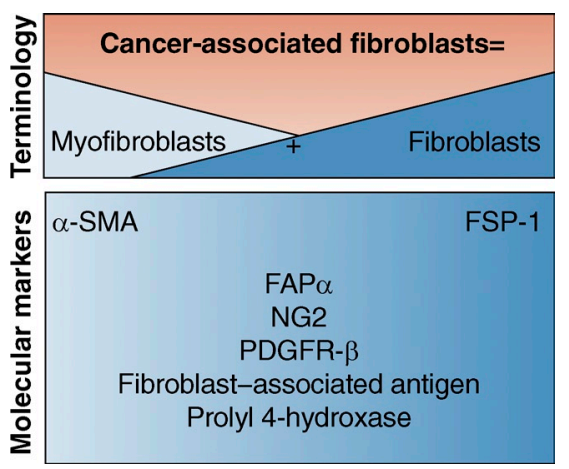

Figure 1. Molecular definition of cancer-associated fibroblasts. CAFs are composed of two morphologically distinctive populations: fibroblasts and myofibroblasts. Indicated are common molecular markers that define CAFs. protease fibroblast-activation protein $\alpha(\mathrm{FAP} \alpha)$ is another common marker for CAFs in many carcinomas including breast, lung, ovarian, and pancreatic (Garin-Chesa et al., 1990). However, FAP $\alpha$ is also not specific to CAFs, as it is highly expressed in quiescent mesodermal cells in multiple tissue types (Roberts et al., 2013), and activated fibroblasts during wound healing and collagen vascular disease (Wang et al., 2005). Another well-studied marker is FSP-1 (also known as S100A4), which seems to play a distinctive and somewhat dual role in cancer, as evident by a protective role of FSP-1-positive cells against carcinogen-mediated malignancy (Zhang et al., 2013a). Yet FSP-1 is also not restricted to CAFs and is also expressed by epithelial cells undergoing EMT (Okada et al., 1997) and bone marrowderived cells, including macrophages, that respond to tissue injury (Österreicher et al., 2011; Cheng et al., 2012). Additional proteins expressed in some CAFs include NG2 (Neuronglial Antigen-2, also known as Chondroitin sulfate proteoglycan), platelet-derived growth factor receptor- $\beta$ (PDGFR- $\beta$ ), fibroblast-associated antigen, and Prolyl 4-hydroxylase (Orimo and Weinberg, 2007). However, these markers are also not unique to CAFs. For example, NG2 is a neural marker that is expressed in the nervous system (Polito and Reynolds, 2005), and PDGFR- $\beta$ expression is also common to vascular smooth muscles, skeletal muscles, and myocardium (Cuttler et al., 2011). PDGFR- $\beta$ was recently reported to be expressed by invasive pancreatic cancer cells (Weissmueller et al., 2014) and thus may also represent a new EMT marker.

It is therefore important to keep in mind that there is currently no marker that completely and exclusively defines CAFs, and this should be taken into account when interpreting results from different models. Moreover, apart from FSP-1, which identifies a unique CAF population, these proteins are often expressed or coexpressed heterogeneously among CAFs, possibly reflecting different stages of activation and sources of CAFs (Fig. 1; Sugimoto et al., 2006).

\section{The origin of CAFs}

Several tissues contribute to the population of CAFs found in an individual tumor (Fig. 2; Xing et al., 2010; Cirri and Chiarugi, 2011). Indeed, numerous cell types have been reported to transdifferentiate to CAFs. The most direct source of CAFs derives from resident tissue fibroblasts and mesenchymal stem cells (MSCs; Rønnov-Jessen and Petersen, 1993; Kojima et al., 2010; Paunescu et al., 2011; Quante et al., 2011;Vicent et al., 2012). The stellate cell is a distinct cell type that shares many of the same functions as fibroblasts. In its quiescent state it is a vitamin A-storing and lipid droplet-containing cell that can be found in the liver, pancreas, kidney, intestine, lung, spleen, uterus, and skin (Kordes et al., 2009). Similar to fibroblasts, stellate cells activate $\alpha$-SMA expression upon stimulation and acquire a myofibroblast-like phenotype. Stellate cells are responsible for the majority of the desmoplastic reaction seen in chronic pancreatitis and pancreatic cancer (Bachem et al., 1998), as 


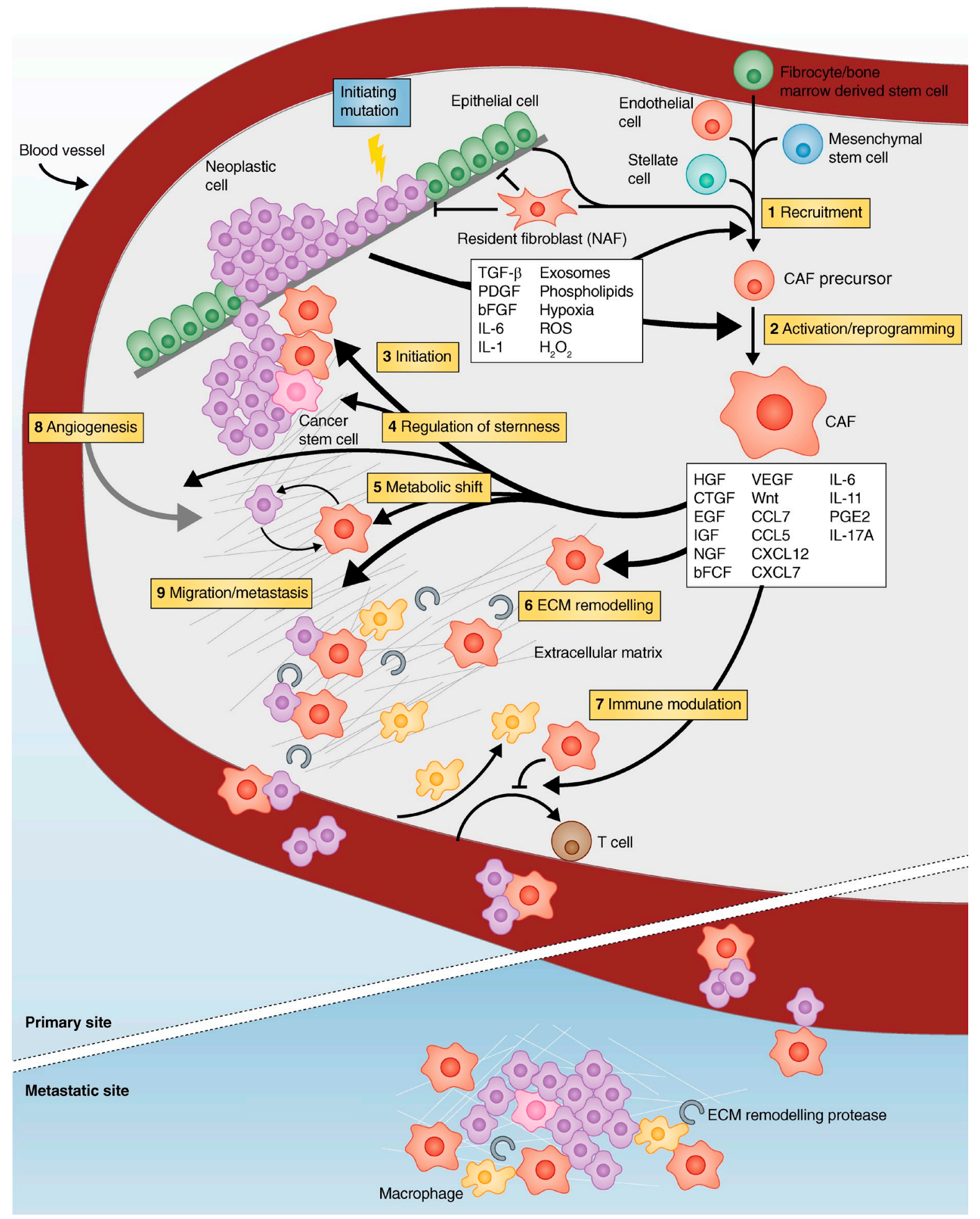

Figure 2. CAFs promote tumorigenesis: a schematic illustration representing all the fronts in which CAFs boost cancer. By secreting soluble factors and lipid-based particles, transformed epithelium drives recruitment (1) and reprogramming (2) of several types of cells into CAFs, including resident fibroblasts (NAFs) that are naturally tumor-suppressive. CAFs are then activated to promote tumor initiation (3), cancer cell stemness (4), and to change tumor metabolism (5) by intensive cross talk of ligands/receptors, cell-cell contact, and remodeling the ECM (6). Concomitantly, CAFs prevent immune surveillance of tumor cells (7) while balancing inflammation and angiogenesis (8). Finally, CAFs stimulate invasion and metastasis by facilitating tumor cell dissemination, intra- and extravasation, and metastatic colonization (9). 
well as in liver fibrosis (Yin et al., 2013), and are categorized as CAFs when seen in cancer tissue. In addition to these local sources of CAFs, bone marrow-derived cells termed fibrocytes can be recruited to the tumor and differentiate into myofibroblasts and fibroblasts (Ishii et al., 2003; Direkze et al., 2004; Mishra et al., 2008; Kidd et al., 2012). $\alpha$-SMAexpressing myofibroblasts have also been shown to originate from neighboring adipose tissue (Kidd et al., 2012). Endothelial-mesenchymal transition (EndMT), a process where endothelial cells down-regulate their CD31 expression and induce expression of FSP-1, is another potential source of CAFs (Zeisberg et al., 2007). FSP-1-positive fibroblasts can also be derived from local epithelial-mesenchymal transition (EMT), indicating that nontransformed epithelial cells may be an additional source of CAFs by undergoing EMT in response to stimuli from surrounding cells (Iwano et al., 2002). Therefore, CAFs may be derived from multiple tissue types, reflecting local and distant cues that are sensed during tumorigenesis, and thus cannot be referred to as one population of cells. The relative contribution of each source of CAFs is highly dependent on the experimental conditions used and less certain in actual human cancers.

\section{Neoplastic cells recruit and activate CAFs}

Early work of Stoker et al. (1966) demonstrated that normal quiescent fibroblasts inhibit the growth of polyomatransformed cells by direct contact between the two cell types. It has later been shown that normal tissue-associated fibroblasts (NAFs) isolated from different organs can inhibit the growth of neoplastic cells (Flaberg et al., 2011), presumably due to the ability of fibroblasts to maintain epithelial homeostasis and proliferative quiescence (Trimboli et al., 2009). Indeed, this has been proposed as one reason why certain tumors found in autopsy studies appear dormant and nonprogressing (Bissell and Hines, 2011). Given these properties of NAFs, neoplastic cells must evolve to both recruit fibroblasts (from the different potential sources mentioned above) and to reprogram them into CAFs, thereby converting the fibroblast from being tumor suppressive to tumor supportive. Interestingly, once reprogrammed, the CAF phenotype can persist in cell culture even in the absence of continued exposure to intratumoral stimuli (Orimo et al., 2005). Several studies have shown that NAFs are functionally distinct from CAFs. Prostate CAFs are more proliferative and less prone to contact inhibition than their NAF counterparts (Madar et al., 2009). Furthermore, colonic CAFs more potently induce the proliferation and migration of neoplastic cells compared with NAFs (Berdiel-Acer et al., 2014).

Oncogenic signaling within neoplastic cells frequently drives the recruitment and activation of fibroblasts by secreting fibroblast-activating factors (Yang et al., 2006), thereby mimicking the normal wound healing process where these factors are normally secreted from injured epithelial cells and macrophages (Fig. 2). TGF- $\beta$ is a major regulator of fibrosis and is one of the most important and well-studied cancer cellderived factors affecting CAF activation (Lieubeau et al., 1994;
Löhr et al., 2001). TGF- $\beta$ binds to the type-2 TGF- $\beta$ receptor (TGFBR2) on the cell surface of fibroblasts, inducing recruitment and phosphorylation of TGFBR 1 and expression of factors involved in paracrine signaling and ECM production and remodeling (Pickup et al., 2013a). Platelet-derived growth factor (PDGF) is also highly expressed in most neoplastic cells, which rarely express PDGF receptors (PDGFRs) themselves. Instead, other cell types, such as CAFs and endothelial cells, express PDGFR (Bronzert et al., 1987; Forsberg et al., 1993), and PDGF has been shown to stimulate proliferation of CAFs and to be an important initiator of the desmoplastic reaction in tumors (Shao et al., 2000). Basic fibroblast growth factor (bFGF) is another mitogen secreted by neoplastic cells that stimulates the proliferation and differentiation of fibroblasts to CAFs (Armelin, 1973; Strutz et al., 2000; Kwabi-Addo et al., 2004). Cytokines produced by neoplastic cells, including IL-6, also stimulate the production of CAFs (Giannoni et al., 2010). In addition, phospholipid derivates, such as lysophosphatidic acid (LPA), can be secreted from neoplastic cells to stimulate differentiation of human MSCs into myofibroblast-like CAFs (Jeon et al., 2008).

Besides growth factors and cytokines, other mechanisms of CAF activation have been reported. For example, exosomes can transfer protein, RNA, and microRNA (miR) from one cell to another, and cancer-derived exosomes have been shown to contribute to the recruitment and activation of fibroblasts and MSCs within tumors (Webber et al., 2010; Cho et al., 2012; Gu et al., 2012; Kahlert and Kalluri, 2013). In addition, hypoxia and reactive oxygen species (ROS) promote activation of CAFs. ROS have been shown to support conversion of fibroblasts into myofibroblasts through the accumulation of the hypoxia-inducible factor (HIF) $-1 \alpha$, whereas antioxidants have been found to reduce HIF-1 $\alpha$ levels, inhibiting numerous myofibroblast features (Toullec et al., 2010).

\section{CAFs modulate the tumor microenvironment}

Upon reprogramming, many transcriptional changes occur that distinguish CAFs from their normal counterparts (Allinen et al., 2004; Nakagawa et al., 2004; Hu et al., 2005). Reprogramming cells into CAFs also involves changes in miR expression, affecting target genes posttranscriptionally (Aprelikova et al., 2010, 2013; Musumeci et al., 2011; Bronisz et al., 2012; Mitra et al., 2012; Masamune et al., 2014). Furthermore, epigenetic changes, such as global DNA hypomethylation frequently seen in neoplastic cells, have also been observed in CAFs (Jiang et al., 2008). Together, all these gene regulatory changes induce a shift in the metabolome and secretome, which maintain the differentiated state of myofibroblasts in an autocrine manner (Kojima et al., 2010) but also stimulate neoplastic cells in a paracrine manner (Fig. 2). In the following sections, we will discuss principle strategies used by activated CAFs to communicate these protumorigenic effects.

CAFs secrete soluble factors. CAFs orchestrate key pathophysiological processes in cancer development through paracrine interactions involving the secretion of multiple soluble 
factors. Growth factors such as hepatocyte growth factor (HGF), connective tissue growth factor (CTGF), epidermal growth factor (EGF), insulin-like growth factor (IGF), nerve growth factor (NGF), basic fibroblast growth factor (bFGF), and members of the Wnt family (Orimo et al., 2001, 2005; Allinen et al., 2004; Bhowmick et al., 2004; Kalluri and Zeisberg, 2006; Erez et al., 2010; Räsänen and Vaheri, 2010; Chaffer and Weinberg, 2011; Cirri and Chiarugi, 2011), as well as many cytokines, such as CCL7 and CXCL12 (Orimo et al., 2005; Jung et al., 2010), have all been reported to be involved in this paracrine cross talk. The CAF secretome also regulates angiogenesis. Vascular endothelial growth factor A (VEGF-A) is induced in CAFs by neoplastic cells (Guo et al., 2008), as well as CXCL12, CXCL14, and CTGF (Orimo et al., 2005; Yang et al., 2005; Augsten et al., 2009). The three most studied CAF-secreted factors will hereafter be discussed in detail.

CXCL12 is highly overexpressed in CAFs (Allinen et al., 2004) and several in vitro and in vivo models have revealed a key role of CXCL12 and its receptor CXCR 4 in tumor-stroma interactions. CXCL12 provides stimulatory input to CXCR4expressing neoplastic cells, resulting in proliferation and migration (Domanska et al., 2012). In pancreatic cancer cells, CXCL12/CXCR4 signaling triggers invasion and EMT through noncanonical Hedgehog pathway (Li et al., 2012c) and further contributes to cancer progression by activation of the canonical Wnt pathway (Wang et al., 2008). CTGF has a key role in fibrosis (Gao and Brigstock, 2005) and is also highly upregulated in numerous cancers (Jacobson and Cunningham, 2012), including pancreatic ductal adenocarcinoma (Charrier and Brigstock, 2013). CTGF expression is induced by TGF- $\beta$ (Pickup et al., 2013a) and hypoxia (Eguchi et al., 2013) in both activated pancreatic stellate cells and neoplastic cells (Hartel et al., 2004) and causes increased invasiveness of neoplastic cells, which can be inhibited through CTGF depletion (Eguchi et al., 2013). In head and neck squamous cancer cells, CTGF enhanced stem-like properties and increased expression of multiple pluripotency genes (Chang et al., 2013). HGF was originally identified as a mitogen for hepatocytes but also plays an important role in wound healing and tissue repair. Normally, HGF is sequestered in the ECM in a latent form. Proteolysis of the latent form of HGF enables binding to and signaling by the c-Met tyrosine kinase (Benvenuti and Comoglio, 2007). The c-Met signaling pathway is often affected in cancer, either by mutations in neoplastic cells leading to constant oncogenic c-Met signaling (Peruzzi and Bottaro, 2006) or by overexpression of HGF in CAFs, leading to increased proliferation of neoplastic cells. Furthermore, in a three-dimensional model of ductal carcinoma in situ, co-cultures with HGF-secreting fibroblasts were found to increase the invasive outgrowth by enhancing the ability of these preneoplastic cells to degrade the ECM (Jedeszko et al., 2009).

CAFs modify tumor metabolism. Metabolic alterations are not only restricted to cancer cells; CAFs also show important metabolic changes that promote tumorigenesis. Fibroblasts are metabolically active already in their quiescent state
(Lemons et al., 2010), but when transformed into CAFs they change their metabolic profile and show increased autophagy (Chaudhri et al., 2013). As an example, phosphoglycerate kinase-1 (PGK1), a part of the glycolytic pathway, is highly up-regulated in CAFs compared with normal fibroblasts. Upon overexpression of PGK1, normal fibroblasts gain a myofibroblastic phenotype, which promotes tumor cell growth when coimplanted with neoplastic cells in vivo (Wang et al., 2010).

Interestingly, CAFs have been reported to use aerobic glycolysis as a source of energy. In some tumors, CAFs express glycolytic enzymes related to the Warburg effect, such as the M2 isoform of pyruvate kinase and lactate dehydrogenase, whereas adjacent neoplastic cells do not (Pavlides et al., 2009). A switch to aerobic glycolysis in CAFs is hypothesized to generate lactate and ketones, which are secreted into the intracellular space and act as paracrine onco-metabolites that fuel oxidative mitochondrial metabolism in neoplastic cells. This phenomenon is referred to as the "reverse Warburg effect" (Pavlides et al., 2009). To further support the significance of this phenomenon, high stromal MTC4 expression (a functional marker of hypoxia, oxidative stress, aerobic glycolysis, and lactate efflux) was shown to be correlated with decreased overall survival in triple-negative breast cancer, whereas expression of MTC4 in neoplastic cells had no prognostic value (Witkiewicz et al., 2012). In ex vivo co-culture systems containing breast cancer cells and fibroblasts, glucose uptake was increased and mitochondria activity was decreased in fibroblasts and the opposite effect was observed in neoplastic cells (MartinezOutschoorn et al., 2011). Mechanistically, neoplastic cells have been shown to secrete $\mathrm{H}_{2} \mathrm{O}_{2}$, which initiates an oxidative stress in the tumor stroma, switching CAFs to aerobic glycolysis (Martinez-Outschoorn et al., 2011). Furthermore, the TGF- $\beta$ pathway in CAFs induces a metabolic reprogramming that promotes mitochondrial activity in adjacent neoplastic cells (Guido et al., 2012). In contrast, other tumors are characterized by the conventional Warburg phenotype in which the neoplastic cells are driven by anaerobic metabolism, and CAFs have been reported to express lactate transporters (MCT1/MCT2) while reducing the expression of glucose transporters (GLUT1; Koukourakis et al., 2006), suggesting a role of CAFs in buffering and recycling the products derived from anaerobic metabolism in neoplastic cell.

There is a great diversity in metabolic phenotype among different tumors. In an attempt to map the metabolic heterogeneity in breast cancer, tumors were classified as having Warburg type (glycolysis in neoplastic cells, nonglycolysis in stroma), reverse Warburg type (nonglycolysis in neoplastic cells, glycolysis in stroma), mixed type (glycolysis in both stroma and neoplastic cells), and null type (nonglycolysis in both stroma and neoplastic cells; Choi et al., 2013). The results indicate a correlation between different metabolic phenotypes and different tumor subtypes (Luminal A, B, triplenegative, etc.).

Collectively, CAFs participate in a dynamic metabolic interplay with the neoplastic cells and can adapt to the metabolic needs of the tumor. This is important to keep in mind when 
targeting metabolic pathways, and it also indicates that PET imaging may be specifically detecting glucose uptake in the tumor stroma rather than in the neoplastic cells in certain tumors.

CAFs remodel the ECM. One characteristic feature of activated CAFs is their ability to synthesize and remodel the ECM in the desmoplastic stroma. Severe desmoplasia is correlated with poor prognosis in lung, pancreas, breast, and colorectal tumors (Cardone et al., 1997; Maeshima et al., 2002; Tsujino et al., 2007; Erkan et al., 2008; Kawase et al., 2008). Changes in the composition and cross-linking of the ECM influence the stiffness of the tissue, which has a pivotal role in tumorigenesis (Erler and Weaver, 2009; Cukierman and Bassi, 2010). By regulating the remodeling of the ECM, CAFs drive the recruitment of other cells into the tumor, promote migration, and facilitate a metastatic phenotype of neoplastic cells.

Hyaluronic acid is a major component of the ECM and CAFs contribute to its production. Apart from serving as a structural component, hyaluronic acid possesses biological functions, such as macrophage recruitment (Kobayashi et al., 2010). Furthermore, CAFs express Lysyl oxidase (LOX), an enzyme responsible for cross-linking collagen I (Pickup et al., 2013b). In breast cancer, tumorigenesis is accompanied by changes in collagen cross-linking, and reduced LOX-mediated collagen cross-linking diminished tumor tissue stiffness and decreased tumor incidence in a xenograft mouse model (Levental et al., 2009).

In contrast, CAFs also regulate the degradation of the ECM. By expressing members of the matrix metalloproteinase (MMP) family, CAFs can facilitate tumor growth, invasion, and metastasis (Poulsom et al., 1992; Stetler-Stevenson et al., 1993; Sternlicht et al., 1999; Vosseler et al., 2009; Zigrino et al., 2009). MMP-mediated ECM remodeling is essential for cancer angiogenesis, and MMP13 expressed from CAFs plays a key role in promoting angiogenesis by releasing VEGF that is bound and sequestered in the ECM (Lederle et al., 2010). In addition, MMPs stimulate protease-activated receptors (PARs) on the surface of neoplastic cells, thereby promoting growth and invasion (Boire et al., 2005). Other proteases are also involved in ECM degradation. For instance, urokinase-type plasminogen activator (uPA) activates the serine protease Plasmin and has thereby been shown to increase proliferation, migration, and invasion (Danø et al., 2005; Noskova et al., 2009). Finally, the CAF marker FAP $\alpha$ is a membrane-bound glycoprotein with both collagenase and dipeptidyl peptidase (DPP) activities that are important for degrading the ECM (Scanlan et al., 1994) and stimulating tumor growth (Cheng et al., 2005).

\section{CAFs trigger tumor initiation and progression}

Many studies have highlighted the importance of CAFs in initiation and progression of cancer mediated by the ability of the CAFs to alter important functions in neoplastic cells, such as cell cycle regulation, migration, and death (Shimoda et al., 2010). Interestingly, neoplastic cells of different origins differ in their responses upon stimulation from CAFs (Kadaba et al., 2013), illustrating a unique relationship with CAFs across tumor types.
By using in vitro co-culture and in vivo transplantation experiments, Olumi et al. (1999) showed that human prostatic CAFs induced the proliferation and the ability to initiate tumors from immortalized nontumorigenic human prostatic epithelial cells. This effect was not manifested by normal fibroblasts and CAFs did not affect growth of normal human prostatic epithelial cells under identical conditions (Olumi et al., 1999). In a similar study, senescent human fibroblasts were shown to stimulate premalignant and malignant, but not normal, epithelial cells to proliferate in culture and develop tumors when engrafted in mice (Krtolica et al., 2001). This elegantly demonstrates how fibroblasts can initiate tumor formation in premalignant cells that have not acquired sufficient genetic alterations for complete transformation. Interestingly, when regrafted into secondary mice in the absence of CAFs, the epithelial cells sustain their tumorigenic potential, showing that the CAF-mediated transformation of epithelial cells is long-lasting (Hayward et al., 2001).

Secreted factors from CAFs are believed to be responsible for this tumor-initiating potential. Although TGF- $\beta$ signaling helps maintain the CAF phenotype, ablating TGFBR in fibroblasts resulted in spontaneous neoplasia in the prostate, illustrating a tumor-suppressive function of TGF- $\beta$ signaling in early tumor development (Bhowmick et al., 2004). Notably, HGF can compensate for TGF- $\beta$ loss, making HGF a candidate for mediating the tumor-initiating effect of CAFs. Indeed, overexpression of HGF in fibroblasts induced hyperproliferation of normal epithelium in a xenograft model (Kuperwasser et al., 2004), which further supports an initiating role of HGF. In addition to tumor initiation, CAFs also participate in tumor maintenance and progression. For example, co-implantation of breast cancer cells with CAFs was shown to increase xenograft tumor growth (Orimo et al., 2005).

Further evidence for the role of CAFs in tumor progression comes from studies in which activated CAFs were inactivated or in which key proteins were reduced in CAFs through genetic ablation. Activated stellate cells in pancreatic cancer could be driven back into a quiescent state by retinoic acid, resulting in reduced paracrine cross talk, such as Wnt/ $\beta$-catenin signaling. In a three-dimensional co-culture system, these quiescent stellate cells slowed tumor progression by reducing neoplastic cell proliferation and migration (Froeling et al., 2011). Mice deficient for the CAF marker FSP-1 also showed reduced engraftment of neoplastic cells and delayed tumor growth (Grum-Schwensen et al., 2005).

\section{CAFs regulate cancer stemness}

There is accumulating evidence for the acquisition of stemlike plasticity in a subset of the cancer cells, usually referred to as cancer stem cells (CSCs). Inflammatory mediators and cytokines are the most common cues reported to induce stemness of neoplastic cells. Many factors secreted by CAFs, such as IL-6, IL-17A, CXCL7, PGE2, and HGF, were shown to trigger the Wnt- $\beta$-catenin pathway in neoplastic cells and augment the CSC population (Giannoni et al., 2010, 2011; Vermeulen et al., 
2010; Liu et al., 2011; Li et al., 2012a; Malanchi et al., 2012; Lotti et al., 2013). CD44, a prominent CSC marker and receptor for hyaluronic acid, is up-regulated in breast, prostate, and colorectal cancers by different cytokines produced by CAFs and contributes to maintaining CSC self-renewal features and general stemness capacity (Giannoni et al., 2010; Liu et al., 2011; Lotti et al., 2013). Interestingly, CD44 is also expressed on CAFs, where it is indispensable for the existence of the neighboring CSC population. In response to hypoxia or reduced nutrient conditions, CAFs elevate CD44 and maintain stem cell properties of neoplastic cells (Kinugasa et al., 2014).

CAFs also induce expression of other CSC markers, such as ALDH1 and Nestin, in many tumor types (Liu et al., 2011; Hamada et al., 2012; Matsuda et al., 2012). Expression of these stem cell markers and the elevation of the CSC population are correlated with aggressive tumors, which exhibit enhanced invasiveness and metastatic capacities (Giannoni et al., 2011; Li et al., 2012a; Malanchi et al., 2012). Together, these data show that CAFs maintain stemness in neoplastic cells to support further tumor progression.

\section{CAFs modulate the immune response}

An inflammatory environment is known to promote errorprone, high-rate proliferation, thereby facilitating tumorigenesis (Grivennikov et al., 2010). Indeed, chronic inflammation is a prominent risk factor for many cancers, including hepatocellular carcinoma, gastric cancer, and pancreatic ductal adenocarcinoma (Pikarsky et al., 2004; Peek and Crabtree, 2006; Guerra et al., 2007). CAFs mediate tumor-enhancing inflammation by expressing a proinflammatory gene signature, which creates a microenvironment that attracts myeloid cells and supports tumor growth and angiogenesis (Erez et al., 2010; Torres et al., 2013). This signature, identified early in dysplastic lesions and maintained throughout tumorigenesis, is mediated via NF-кB-dependent signaling and initiated by IL-1 $\beta$ in skin cancer. Most importantly, normal fibroblasts can be induced by carcinoma cells to turn on this proinflammatory gene signature (Erez et al., 2010). A similar NF-кB-dependent inflammatory signature was activated by CAFs to support prostate cancer stemness and invasion (Giannoni et al., 2011).

Cyclooxygenase 2 (COX2), an NF- $\mathrm{B}$ target involved in mediating inflammation and a part of the proinflammatory gene signature, is expressed by CAFs and neoplastic cells (Nakagawa et al., 2004; Erez et al., 2010), and has been shown to function as a mediator of tumor progression. Indeed, the implantation of lung carcinoma cells in COX2-deficient mice or treatment with COX2 inhibitors reduced tumor growth and vascular density (Williams et al., 2000). In a xenograft model of ductal carcinoma in situ, fibroblasts were shown to induce the expression of COX 2 in neoplastic cells, affecting tumor growth and progression. As a consequence of increased COX2, MMP14 andVEGF expression were increased, causing a more invasive phenotype. Administration of a selective COX2 inhibitor, Celecoxib, impeded this invasion (Hu et al., 2009). Likewise, in vitro coculturing of pancreatic cancer cells with
CAFs increased expression of COX2, and a selective COX2 inhibitor abrogated migration of these cells (Sato et al., 2004).

Genetically altered neoplastic cells often generate neoantigens that can potentially be recognized and destroyed by the immune system. However, most tumors evade immune surveillance despite the abundance of an inflammatory milieu.Accumulating evidence shows that the tumor stroma and CAFs actively participate in modulating the immune response to help neoplastic cells escape detection, thereby supporting tumor progression (Singh et al., 1992; Liao et al., 2009; Iijima et al., 2011). CAFs have been shown to protect pancreatic tumors and lung carcinoma cells from the cytotoxic effect of $\mathrm{T}$ cells via different mechanisms. FAP $\alpha$-positive CAFs were shown to produce CXCL12, which mediated the exclusion of T cells from neoplastic cells (Feig et al., 2013). CAFs also opposed the TNF- and IFN- $\gamma$-mediated necrosis of neoplastic cells by T cells (Kraman et al., 2010). Depletion of FAP $\alpha-$ positive cells restored immunological detection and destruction of the tumor, indicating that FAP $\alpha$-positive cells are immune-suppressive cells in the tumor microenvironment (Kraman et al., 2010; Feig et al., 2013). Additionally, pancreatic stellate cells induce the differentiation of peripheral blood mononuclear cells into immune-suppressive myeloid-derived suppressor cells, contributing to T cell inhibition (Mace et al., 2013). Finally, CAFs derived from hepatocellular carcinoma impair NK cell cytotoxic activity by reducing cytotoxic receptors on their cell surface and interfering with their cytokine production (Li et al., 2012b). This was mediated through the secretion of prostaglandin E2 (PGE2) from CAFs, which also interfered with NK cell functions in melanoma (Balsamo et al., 2009). In summary, CAFs possess the ability to manipulate the immune system, both by excluding and opposing $\mathrm{T}$ and NK cell functions and by maintaining an aberrant inflammatory pro-tumorigenic environment.

\section{CAFs promote cancer cell migration and metastasis}

Neoplastic cell metastasis leads to the demise of most patients, and CAFs participate in this process. Neoplastic cells undergo epigenetic and genetic changes resulting in a metastatic phenotype, and CAFs coevolve with the neoplastic cells during tumor progression by acquiring a proinflammatory gene expression pattern (Saadi et al., 2010). Furthermore, gene signatures characterizing active CAFs are often correlated with poor clinical outcomes (Herrera et al., 2013).

The close proximity between neoplastic cells and CAFs yields an effective cross talk, which ultimately supports invasion and metastasis. TGF- $\beta$ response in CAFs led to secretion of IL-11, which in turn can induce GP130/STAT3 signaling in neoplastic cells to support tumor initiation and accelerate metastasis (Calon et al., 2012). Breast cancer cells also create a paracrine loop by reprogramming their surrounding MSCs into CAFs that secrete CCL5. The cancer cells then responded to CCL5 through the CCR 5 receptor, resulting in augmented metastatic capacity (Karnoub et al., 2007). The noncanonical Wnt-planar cell polarity (PCP) pathway also promotes the dissemination of breast cancer to distant sites in the body. The 
PCP pathway controls convergent-extension movements during embryogenesis and regulates cell motility by changing cell morphology and inducing protrusions. Interestingly, exosomes secreted from CAFs triggered Wnt-11 autocrine induction of the PCP pathway in neoplastic cells, enhancing breast cancer metastatic potential (Luga et al., 2012).

Another important consequence of CAF-mediated signaling on neoplastic cells is EMT, which is considered a critical process in the extravasation of tumors (Guarino et al., 2007). For example, pancreatic stellate cells in pancreatic tumors were shown to trigger EMT in co-cultured neoplastic cells, correlating with increased metastasis (Kikuta et al., 2010). Notch and COX2/NF-кB signaling have also been shown to be involved in acquiring and maintaining the EMT phenotype (Wang et al., 2009b; Li et al., 2012a). Indeed, CAFsecreted MMPs triggered the COX2-NF- $\mathrm{KB}$ cascade in prostate cancer cells to promote ROS accumulation and prostate cancer invasion (Giannoni et al., 2011).

Interestingly, CAFs can promote metastasis in the absence of EMT. CAFs use Rho-dependent signaling pathways to create force-dependent movements by which they migrate and form tracks in the matrix for the neighboring neoplastic cells to follow (Gaggioli et al., 2007; Goetz et al., 2011; Sanz-Moreno et al., 2011). Rho-dependent cytoskeletal remodeling in CAFs was shown to be activated by Palladin, Cav-1, or JAK signaling cascades, and led to Actomyosin contractility and enhanced invasion (Hooper et al., 2010; Goetz et al., 2011; Sanz-Moreno et al., 2011; Brentnall et al., 2012). Mesenchymal-derived Cav-1 also conferred microenvironment remodeling to favor the migration of neoplastic cells. CAFs further facilitated intra- and extravasation and were shown to accompany neoplastic cells to their metastatic site (Duda et al., 2010; Xu et al., 2010). Clusters of cells composed of neoplastic cells and fibroblasts have been shown to be more viable than single neoplastic cells in the blood stream and have a survival advantage when seeding in metastatic sites (Duda et al., 2010). By these means, neoplastic cells can sustain their epithelial features while relying on CAFs for invasion.

CAFs have also been reported to increase the rate of successful colonization by selecting for neoplastic clones bearing a specific metastatic advantage while still residing in the primary lesion. This effect is mediated through the secretion of CXCL12 and IGF (Zhang et al., 2013b). Successful colonization has also been shown to be dependent on proangiogenic factors secreted from FSP-1-positive cells (O'Connell et al., 2011).

\section{CAFs alter therapeutic responses}

The protumorigenic effects of CAFs can also promote therapeutic resistance. Evidence for the clinical relevance of CAFs came from a study by Farmer et al. (2009), who found that breast cancer patients responded poorly to neoadjuvant chemotherapy if their tumors had increased expression of stromal genes. The stroma can interfere with therapeutic agents by two major mechanisms. First, it can simply function as an interstitial barrier that prevents efficient drug delivery (Jain, 1990). The second mechanism involves the activation of signaling pathways that change the therapeutic outcome, driving the neoplastic cell to a more drug-resistant phenotype.

Conversely, a limited number of studies report that CAFs can also increase the anti-neoplastic potency of certain drugs. The mechanism for this unexpected sensitization may include the alteration of signaling pathways in neoplastic cells that are induced by CAFs (McMillin et al., 2013). Although we will not discuss this topic further, it highlights the need to consider the tumor microenvironment during therapeutic development.

Environment-mediated drug resistance. Although acquired drug resistance of neoplastic cells is considered to be a cell autonomous process that leads to adaptive biochemical, epigenetic, or genetic changes, the microenvironment can also participate in this process by providing extrinsic cues that promote cell survival and thereby impede drug toxicity. The impact of the tumor microenvironment on drug resistance was shown previously when mammary cancer cells that were refractory in vivo to cytotoxic drugs became sensitive upon transfer to an in vitro setting where the microenvironment was excluded (Teicher et al., 1990). The importance of the "soil" was further demonstrated in an experiment where colon carcinoma cells were injected at different sites, and showed varying responses to chemotherapy merely based on their location (Fidler et al., 1994). Compared with cell autonomous drug resistance, which develops over a long period of time, environment-mediated resistance can develop rapidly. Thus, environment-mediated resistance may protect neoplastic cells from apoptosis while they acquire the mutations needed for cell-intrinsic protection of chemotherapy (Meads et al., 2009).

Environment-mediated drug resistance can be further categorized into two major groups: soluble factor-mediated drug resistance and cell adhesion-mediated drug resistance (Meads et al., 2009). Soluble factor-mediated drug resistance is induced by cytokines and growth factors secreted from CAFs and other cell types in the stroma. By binding to neoplastic cell receptors, these factors cause transcriptional changes and also activate nontranscriptional mechanisms including degradation or redistribution of activators of apoptosis, and increased stability of suppressors of apoptosis and cell cycle regulators. Resistance due to secreted factors from stromal cells is common, particularly to targeted agents (Straussman et al., 2012). Many cancers have been shown to harbor driving mutations in receptor tyrosine kinase (RTK) pathways, constitutively activating these pathways and making the neoplastic cell "kinase-addicted." Inhibiting these pathways has shown promising results in vitro but many times failed in vivo, where neoplastic cells soon develop resistance to such drugs. Wilson et al. (2012) made it clear that because of redundancy and overlap in many RTK signaling pathways, otherwise kinase-addicted neoplastic cells that respond to certain RTK inhibitors can be rescued from drug sensitivity simply by adding one or more RTK ligands. As CAFs are a major source of secreted RTK ligands, this gives a mechanistic explanation to how CAFs mediate resistance toward targeted therapy. Additional evidence was provided by Wang et al. 
(2009a), who showed that CAFs recruited to lung tumors induced resistance to tyrosine kinase inhibitors against the EGF receptor (EGFR-TKIs). Interestingly, if HGF was inhibited, the resistance to EGFR-TKIs was eliminated, both in vivo and in vitro. This shows the striking impact that a single CAF-secreted growth factor can have on drug resistance.

Moreover, CAFs also play a role in targeted anti-angiogenesis treatments. Crawford et al. (2009) found that the expression of PDGF is up-regulated in CAFs from tumors that are resistant to anti-VEGF therapy and that a PDGF-neutralizing antibody impaired the observed anti-VEGF resistance, suggesting a crucial role for CAFs in mediating resistance to antiangiogenesis therapy.

Soluble factor-mediated drug resistance is also directed against conventional chemotherapies. The CXCL12-CXCR4 signaling axis has been shown to mediate chemotherapy resistance (Singh et al., 2010; Domanska et al., 2012), and furthermore, pancreatic stellate cells drive resistance to chemotherapyinduced apoptosis and radiation-induced apoptosis via a mechanism involving activation of the AKT pathway (Hwang et al., 2008). As mentioned earlier, CAFs also secrete factors that stimulate neoplastic cells to undergo EMT and this process has also been shown to augment resistance to chemotherapy (Wang et al., 2009b).

Cell adhesion-mediated drug resistance occurs when neoplastic cells either adhere to the ECM or make direct cellto-cell contact with stromal cells. Early observations revealed enhanced tumorigenicity and drug resistance when small cell lung cancer (SCLC) cells were grown on a basement membrane (Fridman et al., 1990). Furthermore, if the integrinmediated contact with the ECM was blocked, the tumor load decreased in vivo (Fridman et al., 1990). Adhesion of SCLC cells to the ECM was later shown to enhance tumorigenicity and confer resistance to chemotherapeutic agents as a result of $\beta 1$ integrin-stimulated tyrosine kinase activation, suppressing chemotherapy-induced apoptosis (Sethi et al., 1999). These results provide a mechanistic explanation behind cell adhesionmediated drug resistance. Similar effects have been reported in ovarian cancer (Sherman-Baust et al., 2003) and pancreatic ductal adenocarcinoma cells (Miyamoto et al., 2004). Furthermore, resistance to radiotherapy can also be induced by cell adhesion, and $\beta 1$-integrin-mediated adhesion to fibronectin and collagens has been shown to be essential for cell survival after radiation-induced injury (Cordes et al., 2006).

Finally, cell adhesion can mediate resistance to targeted therapies using the same principles as described for soluble factor-mediated resistance. For example, PI3K/mTOR inhibitors caused cell death in matrix-deprived ovarian cancer spheroids, whereas matrix-attached cells were resistant (Muranen et al., 2012).

Therapy-induced responses in CAFs. Cancer therapies target all cells in vivo, including CAFs, which have been shown to undergo a DNA damage response that paradoxically results in the secretion of proteins that drive tumorigenesis. For example, after exposure to therapeutic agents, CAFs activate canonical Wnt signaling in prostate cancer cells, promoting cancer cell survival and disease progression (Sun et al., 2012). Moreover, when breast cancer cells were injected into the irradiated fat pads of mice, increased neoplastic potential was observed compared with the same cells injected into nonirradiated fat pads (Barcellos-Hoff and Ravani, 2000). Along these lines, irradiated fibroblasts increased invasiveness in pancreatic cancer cells, an effect which could be inhibited with an HGF antagonist (Ohuchida et al., 2004). In addition, Lotti et al. (2013) compared colorectal tumors before and after cytotoxic treatment and found more CAFs in the posttreated tissue. These chemotherapy-treated CAFs, when isolated and co-cultured with CSCs, increased self-renewal, chemoresistance, and tumor growth of CSCs via IL-17A secretion. Collectively, these data illustrate how CAFs can gain new features upon exposure to chemo- or radiotherapy, which not only enables them to reverse or attenuate the effect of anti-cancer drugs but also contributes to a more aggressive cancer phenotype (Barcellos-Hoff et al., 2005).

\section{Targeting the CAF-induced protumorigenic effects}

The broad range of mechanisms used by CAFs to stimulate tumorigenesis and drug resistance (Fig. 2) provides multiple avenues to pursue therapeutic development. Indeed, four general strategies have been suggested to target CAFs and thereby achieve therapeutic benefits: (1) targeting the biophysical stromal barrier to increase drug delivery; (2) sequestering or inhibiting CAF-secreted factors that stimulate neoplastic cell behavior and drug resistance; (3) depleting or blocking the ECM components to reduce adhesionmediated signaling; and (4) targeting the CAFs themselves to disable their downstream effects (Fig. 3).

Many informative experiments testing these strategies have been performed in combination with conventional chemotherapeutic or targeted drugs. The following section will briefly summarize some of the experiments that have provided additional insights to CAF/ECM targeting.

1. Targeting the stromal barrier. The tumor stroma can be considered a barrier that needs to be lowered so that drugs can be optimally delivered. A variety of strategies have been tested to increase drug delivery by overcoming the stromal barrier. Targeting the production of the ECM or degrading the ECM are both feasible strategies to loosen the stroma, resulting in a change in the interstitial pressure of the tumor and the consequent reexpansion of blood vessels. Hyaluronic acid, TGF- $\beta$, and the Hedgehog pathway have all been tested as targets in this context.

High interstitial fluid pressure is evident in solid tumors, especially those rich in ECM, resulting in vascular collapse and effectively limiting perfusion and diffusion (Provenzano et al., 2012). Hyaluronic acid compresses vessels in collagenrich tumors, and both collagen and hyaluronic acid are critical targets for decompressing tumor vessels. Enzymatic degradation of hyaluronic acid using hyaluronidase normalized the interstitial fluid pressure and expanded the microvasculature, 

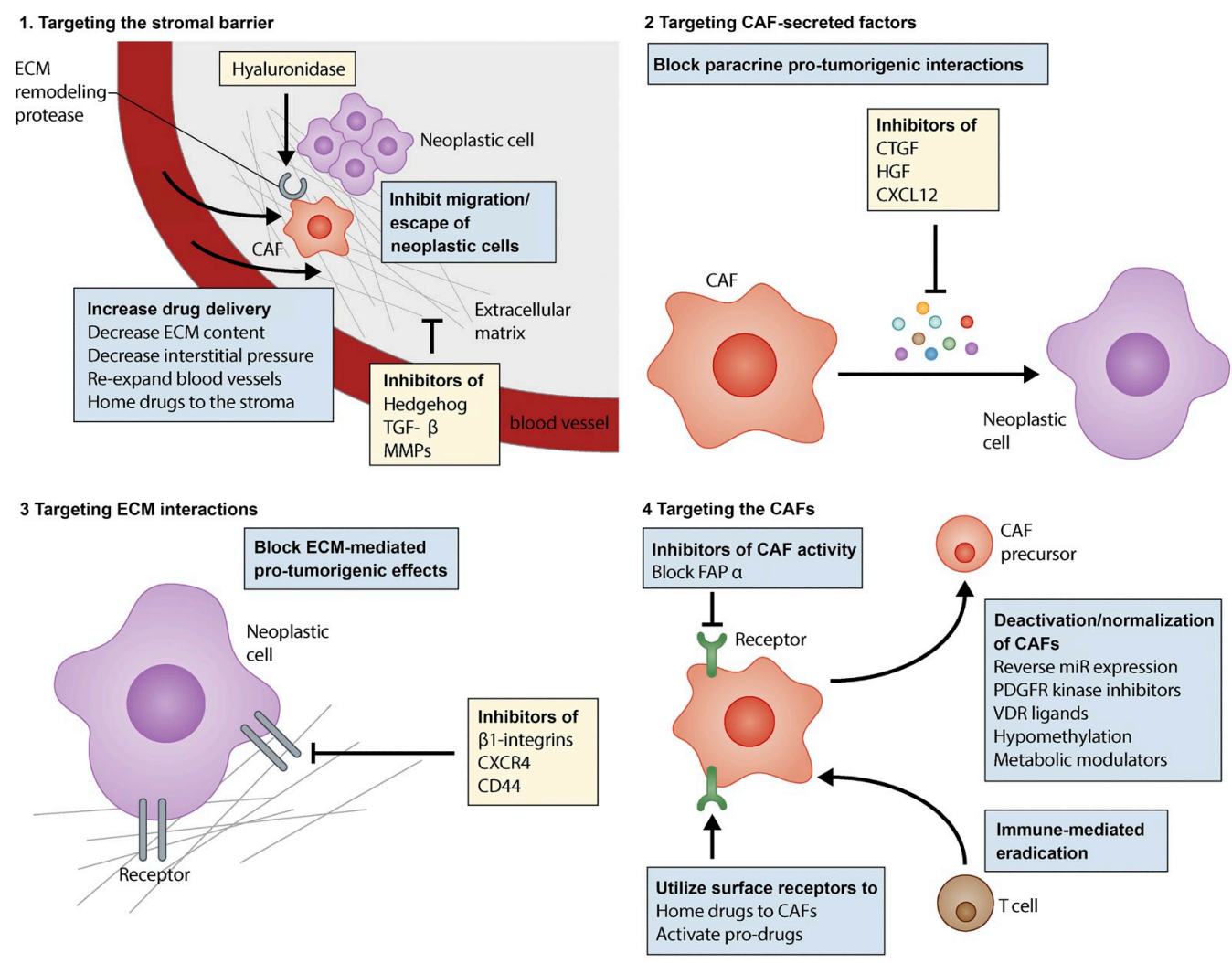

Figure 3. Principle strategies for targeting CAF-induced pro-tumorigenic effects. Presented are four general approaches to control and diminish CAFs and their activity toward tumorigenesis and drug resistance. Examples of targets that have been hypothesized and/or empirically tested are indicated.

leading to increased intratumoral delivery of chemotherapeutic agents (Provenzano et al., 2012; Jacobetz et al., 2013). Accordingly, the combination of hyaluronidase and conventional chemotherapy inhibited tumor growth and prolonged survival relative to monotherapy in mouse models of pancreatic cancer (Provenzano et al., 2012; Jacobetz et al., 2013). This concept is now being tested in clinical trials.

Inhibitors of TGF- $\beta$ were shown to decrease collagen I content and increase the fraction of perfused vessels in a mouse breast cancer orthotopic model, leading to preclinical benefit. Furthermore, the normalization of the tumor stroma improved intratumoral delivery of conventional chemotherapeutic drugs, leading to better drug response (Liu et al., 2012).TGF- $\beta$ inhibitors are also capable of inhibiting cancer progression in animal models (Akhurst and Hata, 2012), but this pathway is highly context-dependent and complicated to target. Indeed, TGF- $\beta$ signaling exhibits a seemingly biphasic action during tumorigenesis, being tumor-suppressive early in tumorigenesis and becoming tumor-promoting in later stages. Indirectly targeting MMPs by inhibiting the TGF- $\beta$ pathway is an alternative mechanism by which the stromal barrier may be attenuated. Low doses of the TGF-type I receptor inhibitor have been shown to increase the delivery of anti-cancer nanocarriers, thereby potentiating their tumor-inhibitory effect without altering eitherTGF signaling in neoplastic cells or the amount of fibrosis (Kano et al., 2007). Given that TGF- $\beta$ and MMP14 are both involved in a pathway that regulates vessel stability, inhibiting this pathway may increase delivery efficacy by increasing perfusion of the tumor (Sounni et al., 2010).

Angiotensin receptor blockers (ARBs) were originally developed for the treatment of hypertension but also inhibit TGF- $\beta$ signaling (Diop-Frimpong et al., 2011), although the exact mechanism for this is unclear. Nevertheless, the Angiotensin signaling pathway is activated in stellate cells and contributes to the desmoplastic reaction (Sakurai et al., 2011). ARBs have been shown to inhibit the production of collagen I by CAFs (Diop-Frimpong et al., 2011), and in a subcutaneous xenograft mouse model, ARB reduced expression of $\alpha$-SMA in the tumor, resulting in reduced ECM and tumor inhibition (Masamune et al., 2013). By reducing collagen and hyaluronic acid production, $A R B s$ can increase vascular perfusion and drug delivery (Chauhan et al., 2013). A retrospective study further suggested the role of the Angiotensin pathway in cancer by showing that pancreatic cancer patients that underwent gemcitabine monotherapy and at the same time received hypertension treatment with ARB had a significantly better survival than patients without ARB treatment (Nakai et al., 2010).

Hedgehog $(\mathrm{Hh})$ signaling mediates tumorigenesis in many types of cancer (Thayer et al., 2003; Bailey et al., 2009). Interestingly, despite ligand production in neoplastic cells, Hh signaling is not activated in these cells. Instead, CAFs have been 
demonstrated to respond to Hh stimulation by increasing the production of ECM (Yauch et al., 2008), indirectly supporting tumor growth. An inhibitor of Hh signaling, IPI-926, resulted in stromal depletion in a mouse model of pancreatic cancer. In combination with gemcitabine, IPI-926 increased the intratumoral vascular density, perfusion, and intratumoral concentration of chemotherapy, correlating with transient growth inhibition (Olive et al., 2009). Importantly, this study and the aforementioned studies targeting hyaluronan showed that by depleting the stroma barrier, drug delivery is increased, resulting in transiently improved survival. Although the combination of IPI-926 and chemotherapy was promising in a Phase I trial, this approach failed in a randomized phase II clinical trial. To address these conflicting data, a follow-up study was recently conducted, where $\mathrm{Hh}$ was genetically ablated in the epithelial compartment of a pancreatic cancer mouse model. Interestingly, despite a decreased number of stromal cells and an increased vascularization, these tumors were more aggressive and tended to be much less differentiated, subsequently leading to reduced survival of these mice (Rhim et al., 2014). Similar results were obtained in another study, where depletion of cancer-associated myofibroblasts in a pancreatic cancer model led to more aggressive and less differentiated tumors (Özdemir et al., 2014). Thus, the protective role of certain stromal elements should be kept in mind, although further interrogation of this phenomenon in other settings is required to evaluate the physiological role of the stroma in restraining cancer.

MMP inhibitors are another example that illustrates the complexity of the tumor stroma. These inhibitors were developed to block the degradation of the ECM, a process which was predicted to facilitate tumor progression. Early preclinical studies with MMP inhibitors were promising; however, randomized clinical trials were not positive (Dufour and Overall, 2013). An explanation for this may lie in the fact that MMPs have many different substrates, and besides ECM structures, they also affect chemokines and cell surface receptors that might have tumor suppressive effects (Dufour and Overall, 2013). Unfortunately, side effects limited the dosing of the MMP inhibitor, and therefore the results of this trial may be misleading.

It is also possible to use the tumor ECM as a homing signal for drugs, limiting reactivity to normal tissues. By conjugating drugs to antibodies or small molecules that recognize stromal epitopes, drugs can be accumulated in the tumor, limiting the area of cytotoxicity. For instance, the plasminogen activator inhibitor type 2 (PAI2) has high affinity to plasminogen activator (uPA), which is highly expressed in the stroma of pancreatic cancer. By conjugating a radioisotope onto PAI2, radioactivity was concentrated in the tumor and caused complete inhibition of tumor growth in a xenograft model (Qu et al., 2005). Additionally, nAb-Paclitaxel, an albumin-formulated Paclitaxel, was hypothesized to bind to the matricellular protein Osteonectin/SPARC that is present in many tumor types and thereby cause stromal depletion. This hypothesis was supported by data from patientderived pancreatic cancer xenografts that demonstrated stromal loss after treatment (Von Hoff et al., 2011), and from resected specimens of patients who were treated with nAb-Paclitaxel and gemcitabine that demonstrated loss of neoplastic cells and a deficient stroma (Alvarez et al., 2013). However, direct experiments in genetic mouse models did not corroborate stromal loss as the primary mode of action for $\mathrm{nAb}$-paclitaxel but rather implicated drug-drug interactions leading to increased neoplastic cell death as an important aspect of its activity (Frese et al., 2012). Furthermore, mice harboring pancreatic tumors and lacking SPARC responded to $\mathrm{nAb}-$ Paclitaxel in an indistinguishable manner compared with mice that expressed SPARC (Neesse et al., 2014). To reconcile these seemingly contradictory findings, it is logical that the loss of neoplastic cells will lead to secondary decreases in stromal abundance.

2. Targeting CAF-secreted factors. CAFs secrete a variety of mitogens, chemokines, and matricellular proteins that promote tumor progression and drug resistance. Neesse et al. (2013) showed that targeting the stroma in a mouse pancreatic cancer model with a CTGF antibody yielded a synergistic effect with gemcitabine without increasing the intratumoral gemcitabine concentration. Mechanistic analysis revealed that CTGF deregulates the expression of the apoptosis modulating protein XIAP, highlighting the impact that secreted factors from CAFs have on neoplastic cells in terms of response to therapy. This modality is currently undergoing clinical investigation.

The HGF-Met pathway has been interrogated in many preclinical studies, either as monotherapy or in combination with other drugs. For example, a competitive antagonist of c-Met (NK4) has been shown to reduce liver metastasis and prolong survival in a mouse model of colon cancer (Wen et al., 2004). Furthermore, stromal fibroblast-secreted HGF is involved in mediating therapy resistance in melanoma. BRAF mutant melanomas are highly dependent on constitutive BRAF kinase activity, and inhibition of BRAF improves survival in patients (Bollag et al., 2010; Flaherty et al., 2010; Chapman et al., 2011; Sosman et al., 2012). However, CAF-derived HGF and subsequent activation of the HGF receptor $\mathrm{c}-\mathrm{Met}$ have been shown to mediate resistance to targeted RAF inhibition. Interestingly, targeting both RAF and c-Met reversed the observed resistance (Straussman et al., 2012), illustrating how microenvironment-derived mediators of drug resistance can serve as promising targets to overcome the resistance problem with targeted therapies seen in the clinic.

The CXCR 4 antagonist AMD3100 was shown to chemosensitize prostate cancer cells to the chemotherapeutic agent docetaxel in a synergistic manner (Domanska et al., 2012). As discussed previously, CXCL12 secreted from FAP $\alpha$-positive cells was shown to be important for immune suppression in pancreatic cancer, providing a conceivable explanation as to why immunological checkpoint antagonists, such as anti-PDL1, have failed in pancreatic cancer (Royal et al., 2010). Notably, in a mouse model of pancreas cancer, CXCR 4 inhibition promoted $\mathrm{T}$ cell accumulation in the tumor site and synergized potently with anti-PDL1 (Feig et al., 2013). 
3. Targeting ECM interactions. Neoplastic cells interact with the ECM using a variety of cell surface receptors, of which integrins are the most studied. In a three-dimensional culture system of breast cancer, a $\beta 1$-integrin inhibitor induced apoptosis and inhibited growth of breast cancer cells, highlighting the therapeutic potential of blocking integrin interactions with the ECM (Park et al., 2006). Furthermore, $\beta 1$-integrin inhibitors synergized with radiation therapy to increase apoptosis and inhibit tumor growth in a mouse xenograft model (Park et al., 2008). Integrin antagonists have therefore been tested in clinical trials (Mullamitha et al., 2007; Reardon et al., 2008), and although they were well tolerated, clinical benefits have not yet been demonstrated. CD44 expressed by neoplastic cells allows an additional interacting point with the ECM. It binds to collagen and hyaluronic acid, and certain isoforms of CD44 provide survival signals in neoplastic cells (Bourguignon et al., 2003; Götte and Yip, 2006). Abrogating CD44-ECM interactions has been shown to inhibit tumor growth in xenograft models (Ahrens et al., 2001); however, this awaits clinical confirmation.

Soluble factors secreted from CAFs can also indirectly regulate adhesion of neoplastic cells. For example, CXCL12-induced integrin activation was found to increase adhesion of SCLC cells to fibronectin and collagen and thereby protects SCLC cells from chemotherapy-induced apoptosis (Hartmann et al., 2005).

4. Targeting the CAFs. Normalization of CAF behavior to change their properties to a more "non-myofibroblastic" phenotype can be achieved by multiple mechanisms. One way is by targeting epigenetic changes unique for CAFs. Many groups have recently shown that therapies aimed at reconstituting miR expression might be a successful strategy to deactivate CAFs (Musumeci et al., 2011; Bronisz et al., 2012; Mitra et al., 2012; Aprelikova et al., 2013). Inhibition of PDGF signaling, an important pathway in the activation of CAFs, can reverse CAFs to normal fibroblasts (Haubeiss et al., 2010). Using a clinically approved PDGFR kinase inhibitor (Imatinib) in a mouse model of cervical carcinogenesis, tumor proliferation was reduced and angiogenesis was inhibited. Furthermore, the progression of premalignant cervical lesions was attenuated and the growth of preexisting invasive carcinomas was impaired (Pietras et al., 2008). Because CAFs undergo changes in their metabolic activity, normalization of the metabolic phenotype and inhibition of metabolic pathways have also been suggested as a plausible way to target tumors (Witkiewicz et al., 2012; Doherty and Cleveland, 2013).

Another approach to target the CAFs would be to dedifferentiate them into a quiescent state. Hepatic stellate cells play a crucial role in liver fibrosis and in the desmoplastic reaction in liver cancer and are known to express several nuclear hormone receptors including the vitamin D receptor (VDR). Ding et al. (2013) demonstrated that VDR ligands promoted the dedifferentiation of stellate cells and abrogated fibrosis, stressing the potential use of VDR ligands to target CAFs. Taking advantage of existing epigenetic changes has also been suggested as a means to induce CAF arrest. Treatment of CAFs with hypomethylating drugs is hypothesized to result in a "hypomethylation crisis" by causing further demethylation in the already hypomethylated CAF genomes (Gonda et al., 2010), resulting in growth arrest.

Finally, FAP $\alpha$ has been proposed as a potential therapeutic target (Brennen et al., 2012). This serine protease is expressed on most CAFs. Blocking FAP $\alpha$ was found to inhibit tumor growth, and to decrease myofibroblast content and blood vessel density in lung and colon tumors (Santos et al., 2009). Furthermore, a phase I trial showed that FAP $\alpha$ can be targeted without apparent side effects (Scott et al., 2003). However, no significant efficacy was shown for the treatment of metastatic colorectal cancer (Hofheinz et al., 2003).

FAP $\alpha$ can also be used to deliver cytotoxic drugs to the CAFs. An anti-FAP $\alpha$ antibody conjugated to an anti-mitotic agent induced long-lasting inhibition of tumor growth in xenograft models (Ostermann et al., 2008). Investigators have also used the proteolytic activity of FAP $\alpha$ to target CAFs. By delivering an inert pro-drug that contains the FAP $\alpha$ cleavage site, FAP $\alpha$-positive cells in the tumor stroma can cleave and activate the drug, a method which has been tested both in vitro (Huang et al., 2011) and in xenograft models (LeBeau et al., 2009), resulting in a significant growth inhibition.

In addition, FAP $\alpha$ is a target selected for immunotherapy experiments. Cancer mouse models have been immunized against FAP $\alpha$-positive cells, resulting in tumor growth inhibition (Lee et al., 2005). Also, an oral DNA vaccine directed against FAP $\alpha$-positive cells caused $\mathrm{CD}^{+} \mathrm{T}$ cell-mediated killing of CAFs and suppression of primary tumor growth and metastasis, accompanied by a greater intratumoral uptake of chemotherapeutic drugs and improved drug response (Loeffler et al., 2006). In spite of the successful preclinical results, no FAP $\alpha$-directed agents are currently in clinical practice (Brennen et al., 2012).

\section{Concluding remarks}

Based on the body of evidence now available, it is clear that the tumor microenvironment is involved in all stages of tumorigenesis, shaping how neoplastic cells respond to targeted therapies, chemotherapies, or radiotherapy. Thus, the tumor microenvironment has significant impact on clinical outcome. Unfortunately, preclinical drug testing has been largely restricted to two dimensional cell culture systems or subcutaneous xenograft murine models, without fully incorporating a relevant tumor microenvironment. This lack of tumor stroma in cancer models may reflect the lack of efficacy seen in later clinical trials of many drugs. Therefore, it is of high priority to transfer preclinical drug development to platforms that take stromal interactions into account.

CAFs are tempting drug targets for many reasons. They are genetically more stable then neoplastic cells, making them less prone to develop resistance phenotypes as a result of high mutation rates and clonal selection. Additionally, CAFs show epigenetic changes that distinguish them from normal stromal cells, and furthermore, the composition of the cancerassociated stroma is distinct from normal stroma. This presents 
opportunities to find unique drug targets that do not affect normal physiology. In addition, CAFs in some cases cause sensitization to certain drugs, giving a rationale for the use of inhibitors against pathways that are activated by CAFs in neoplastic cells. Moreover, CAFs have the potential to activate pathways that mediate resistance to targeted anti-neoplastic agents, and resistance may be avoided if CAF-derived stimuli are neutralized. Finally, CAFs accompany and support neoplastic cells during the whole spectrum of the disease, from preinvasive lesions all the way to the metastatic site. By targeting CAFs, different stages of the disease and also many different pathophysiological processes may become treatable, including angiogenesis, EMT, and immune evasion.

Developing combinatorial therapies that target both the CAFs and the neoplastic cells holds promise for synergistic effects. If neoplastic cells are dependent on a certain input from the CAFs, it is reasonable to assume that depleting this input would make the neoplastic cells more vulnerable and less resistant to a second line of treatment with conventional therapies. Rationale supporting this hypothesis was provided by a study where pretreatment with drugs targeting oncogenic signaling pathways sensitized breast carcinoma cells to conventional chemotherapy (Lee et al., 2012). In addition, some conventional therapies potentiate the pro-tumorigenic effects of CAFs, conferring an even more aggressive cancer phenotype. This effect may be avoided if the CAFs were targeted first. Finally, drug delivery in a second round of therapy would be improved in the absence of CAFs, the major constituent of the stroma barrier.

CAFs represent a very heterogeneous population of cells, and each subpopulation might have different pathophysiological functions. Some CAFs might also have tumor-suppressive roles by preventing neoplastic cell proliferation or migration. It is in no way excluded that certain CAFs, and also other components within the tumor-associated stroma, are induced as a result of a host-driven response to the neoplastic cells. In fact, cancer progression in vivo is a relatively slow process compared with what is observed in vitro. Autopsy studies show that many preneoplastic lesions, despite harboring dominant genetic alterations sufficient to promote tumorigenesis, remain dormant. Emerging data further reinforce this idea of CAFs as a double-edged sword in tumorigenesis by demonstrating that ablation of a single cue from epithelial cells to stromal cells (Rhim et al., 2014), or depletion of the entire myofibroblastic population (Özdemir et al., 2014), accelerates pancreatic cancer. These studies question the general dogma of the field and illustrate how components in the microenvironment actually inhibit cancer progression. These findings further enlighten the complex nature of the tumor stroma; however, the implications of these findings are yet to be determined in a broader perspective. Also, it is important to keep in mind that rapidly developing tumors in murine cancer models driven by one or a few defined mutations might not fully recapitulate the complexity of the tumor microenvironment seen in human tumors. This provides a probable explanation as to why some approaches resulting in a global depletion of the tumor-associated stroma can show promising results in mouse models but cause increased tumor growth when applied to patients. It also raises the idea that the targets within the stroma must be specific and cannot cause a general and unselective depletion of the stroma or the CAFs. Another pitfall is that researchers often study a specific subpopulation of CAFs, based on one or a few expressed markers, but interpret the data as true for all populations of CAFs. The term "cancer-associated fibroblast" is therefore somewhat misleading, as it groups cells of different origin merely based on their location despite their heterogeneity and diverse roles in tumorigenesis. It is important to keep in mind that the only feature that unites the CAFs are their ability to alter the microenvironment and the behavior of neoplastic cells, but this can result in either a pro- or anti-tumorigenic effect. Efforts must therefore be put into resolving the complexity of the tumor stroma and understanding the unique roles of the different subpopulations of CAFs.

Traditionally, cancer is viewed as a result of clonal expansion, where neoplastic cells constantly undergo selection and the clones that constitute late-stage tumors are the ones most fit to avoid the host response and given therapies. However, when an initiating preneoplastic cell emerges, it does so in the context of its microenvironment, which then coevolves during the whole process of tumorigenesis such that both entities develop a symbiotic relationship that promotes tumor growth. Thus, what is seen in patients is a selected population of CAFs and neoplastic cells that collectively survives and thrives. It is vital for a neoplastic cell to achieve the ability to reprogram normal stromal cells into CAFs and by this influence to modulate the microenvironment. This process represents a fundamental and crucial hallmark of cancer. Neoplastic cells that fail to develop this capacity will not pass critical barriers in tumorigenesis and will remain dormant. Therefore, understanding the interplay between neoplastic cells and their microenvironment is critical, especially in the initiation of cancer. Further insights in this process have the potential to reveal relevant discoveries with subsequent clinical implications.

We thank Lindsey A. Baker, Vincenzo Corbo, Christine Chio, Mariano Ponz-Sarvise, Dannielle Engle, Abram Handly-Santana, and Tobiloba Oni for critical feedback on the manuscript.

Daniel Öhlund is supported by the Swedish Research Council (537-2013-7277), The Kempe Foundations (JCK-1301), and The Swedish Society of Medicine (SLS326921, SLS-250831). Ela Elyada is supported by the Human Frontiers Science Program (LT000403/2014) and by the Weizmann Institute of Science Women in Science award. David Tuveson is supported by the Lustgarten Foundation for Pancreatic Cancer Research, the Cold Spring Harbor Laboratory Association, the Carcinoid Foundation, the STARR foundation (I7-A718), PCUK, DOD (W81XWH-13PRCRP-IA), and the National Institutes of Health (5P30CA45508-26, 5P50CA101955-07, 1U10CA180944-01, and 5U01CA168409-3).

The authors declare no competing financial interests.

Submitted: 11 April 2014

Accepted: 18 June 2014

\section{REFERENCES}

Ahrens, T., J.P. Sleeman, C.M. Schempp, N. Howells, M. Hofmann, H. Ponta, P. Herrlich, and J.C. Simon. 2001. Soluble CD44 inhibits melanoma tumor growth by blocking cell surface CD44 binding to hyaluronic acid. Oncogene. 20:3399-3408. http://dx.doi.org/10.1038/sj.onc.1204435

Akhurst, R.J., and A. Hata. 2012. Targeting the TGF $\beta$ signalling pathway in disease. Nat. Rev. Drug Discov. 11:790-811. http://dx.doi.org/ $10.1038 / \operatorname{nrd} 3810$ 
Allinen, M., R. Beroukhim, L. Cai, C. Brennan, J. Lahti-Domenici, H. Huang, D. Porter, M. Hu, L. Chin, A. Richardson, et al. 2004. Molecular characterization of the tumor microenvironment in breast cancer. Cancer Cell. 6:17-32. http://dx.doi.org/10.1016/j.ccr.2004.06.010

Alvarez, R., M. Musteanu, E. Garcia-Garcia, P.P. Lopez-Casas, D. Megias, C. Guerra, M. Muñoz, Y. Quijano, A. Cubillo, J. Rodriguez-Pascual, et al. 2013. Stromal disrupting effects of nab-paclitaxel in pancreatic cancer. Br. J. Cancer. 109:926-933. http://dx.doi.org/10.1038/bjc.2013.415

Anderberg, C., and K. Pietras. 2009. On the origin of cancer-associated fibroblasts. Cell Cycle. 8:1461-1465. http://dx.doi.org/10.4161/cc.8.10.8557

Aprelikova, O., X. Yu, J. Palla, B.-R. Wei, S. John, M. Yi, R. Stephens, R.M. Simpson, J.I. Risinger, A. Jazaeri, and J. Niederhuber. 2010. The role of miR-31 and its target gene SATB2 in cancer-associated fibroblasts. Cell Cycle. 9:4387-4398. http://dx.doi.org/10.4161/cc.9.21.13674

Aprelikova, O., J. Palla, B. Hibler, X. Yu, Y.E. Greer, M.Yi, R. Stephens, G.L. Maxwell, A. Jazaeri, J.I. Risinger, et al. 2013. Silencing of miR-148a in cancer-associated fibroblasts results in WNT10B-mediated stimulation of tumor cell motility. Oncogene. 32:3246-3253. http://dx.doi.org/ 10.1038/onc.2012.351

Armelin, H.A. 1973. Pituitary extracts and steroid hormones in the control of 3 T3 cell growth. Proc. Natl. Acad. Sci. USA. 70:2702-2706. http:// dx.doi.org/10.1073/pnas.70.9.2702

Augsten, M., C. Hägglöf, E. Olsson, C. Stolz, P. Tsagozis, T. Levchenko, M.J. Frederick, A. Borg, P. Micke, L. Egevad, and A. Ostman. 2009. CXCL14 is an autocrine growth factor for fibroblasts and acts as a multi-modal stimulator of prostate tumor growth. Proc. Natl.Acad. Sci. USA. 106:34143419. http://dx.doi.org/10.1073/pnas.0813144106

Bachem, M.G., E. Schneider, H. Gross, H. Weidenbach, R.M. Schmid, A. Menke, M. Siech, H. Beger, A. Grünert, and G. Adler. 1998. Identification, culture, and characterization of pancreatic stellate cells in rats and humans. Gastroenterology. 115:421-432. http://dx.doi.org/10 .1016/S0016-5085(98)70209-4

Bailey, J.M., A.M. Mohr, and M.A. Hollingsworth. 2009. Sonic hedgehog paracrine signaling regulates metastasis and lymphangiogenesis in pancreatic cancer. Oncogene. 28:3513-3525. http://dx.doi.org/10.1038/onc .2009 .220

Balsamo, M., F. Scordamaglia, G. Pietra, C. Manzini, C. Cantoni, M. Boitano, P. Queirolo, W. Vermi, F. Facchetti, A. Moretta, et al. 2009. Melanomaassociated fibroblasts modulate NK cell phenotype and antitumor cytotoxicity. Proc. Natl.Acad. Sci. USA. 106:20847-20852. http://dx.doi.org/ 10.1073/pnas.0906481106

Barcellos-Hoff, M.H., and S.A. Ravani. 2000. Irradiated mammary gland stroma promotes the expression of tumorigenic potential by unirradiated epithelial cells. Cancer Res. 60:1254-1260.

Barcellos-Hoff, M.H., C. Park, and E.G. Wright. 2005. Radiation and the microenvironment - tumorigenesis and therapy. Nat. Rev. Cancer. 5:867-875. http://dx.doi.org/10.1038/nrc1735

Benvenuti, S., and P.M. Comoglio. 2007. The MET receptor tyrosine kinase in invasion and metastasis. J. Cell. Physiol. 213:316-325. http://dx doi.org/10.1002/jcp. 21183

Berdiel-Acer, M., R. Sanz-Pamplona, A. Calon, D. Cuadras, A. Berenguer, X Sanjuan, M.J.Paules, R. Salazar,V.Moreno,E.Batlle, et al.2014.Differences between CAFs and their paired NCF from adjacent colonic mucosa reveal functional heterogeneity of CAFs, providing prognostic information. Mol. Oncol. http://dx.doi.org/10.1016/j.molonc.2014.04.006

Bhowmick, N.A., A. Chytil, D. Plieth, A.E. Gorska, N. Dumont, S. Shappell, M.K.Washington, E.G. Neilson, and H.L. Moses. 2004.TGF- $\beta$ signaling in fibroblasts modulates the oncogenic potential of adjacent epithelia. Science. 303:848-851. http://dx.doi.org/10.1126/science.1090922

Bissell, M.J., and W.C. Hines. 2011. Why don't we get more cancer? A proposed role of the microenvironment in restraining cancer progression. Nat. Med. 17:320-329. http://dx.doi.org/10.1038/nm.2328

Bizik, J., E. Kankuri, A. Ristimäki, A. Täeb, H. Vapaatalo, W. Lubitz, and A Vaheri. 2004. Cell-cell contacts trigger programmed necrosis and induce cyclooxygenase-2 expression. Cell Death Differ. 11:183-195. http://dx .doi.org/10.1038/sj.cdd.4401317

Boire, A., L. Covic, A. Agarwal, S. Jacques, S. Sherifi, and A. Kuliopulos. 2005. PAR1 is a matrix metalloprotease-1 receptor that promotes invasion and tumorigenesis of breast cancer cells. Cell. 120:303-313. http:// dx.doi.org/10.1016/j.cell.2004.12.018

Bollag, G., P. Hirth, J. Tsai, J. Zhang, P.N. Ibrahim, H. Cho, W. Spevak, C. Zhang, Y. Zhang, G. Habets, et al. 2010. Clinical efficacy of a RAF inhibitor needs broad target blockade in BRAF-mutant melanoma. Nature. 467:596-599. http://dx.doi.org/10.1038/nature09454

Bourguignon, L.Y., P.A. Singleton, H.Zhu, and F.Diedrich. 2003. Hyaluronanmediated CD44 interaction with RhoGEF and Rho kinase promotes Grb2-associated binder-1 phosphorylation and phosphatidylinositol 3-kinase signaling leading to cytokine (macrophage-colony stimulating factor) production and breast tumor progression. J. Biol. Chem. 278: 29420-29434. http://dx.doi.org/10.1074/jbc.M301885200

Brennen, W.N., J.T. Isaacs, and S.R. Denmeade. 2012. Rationale behind targeting fibroblast activation protein-expressing carcinoma-associated fibroblasts as a novel chemotherapeutic strategy. Mol. Cancer Ther. 11:257266. http://dx.doi.org/10.1158/1535-7163.MCT-11-0340

Brentnall, T.A., L.A. Lai, J. Coleman, M.P. Bronner, S. Pan, and R. Chen. 2012 Arousal of cancer-associated stroma: overexpression of palladin activates fibroblasts to promote tumor invasion. PLoS ONE. 7:e30219. http:// dx.doi.org/10.1371/journal.pone.0030219

Bronisz, A., J. Godlewski, J.A. Wallace, A.S. Merchant, M.O. Nowicki, H. Mathsyaraja, R. Srinivasan, A.J. Trimboli, C.K. Martin, F. Li, et al. 2012. Reprogramming of the tumour microenvironment by stromal PTENregulated miR-320. Nat. Cell Biol. 14:159-167. http://dx.doi.org/10 $.1038 /$ ncb2396

Bronzert, D.A., P. Pantazis, H.N. Antoniades, A. Kasid, N. Davidson, R.B. Dickson, and M.E. Lippman. 1987. Synthesis and secretion of plateletderived growth factor by human breast cancer cell lines. Proc. Natl. Acad. Sci. USA. 84:5763-5767. http://dx.doi.org/10.1073/pnas.84.16.5763

Calon, A., E. Espinet, S. Palomo-Ponce, D.V. Tauriello, M. Iglesias, M.V. Céspedes, M. Sevillano, C. Nadal, P. Jung, X.H. Zhang, et al. 2012. Dependency of colorectal cancer on a TGF- $\beta$-driven program in stromal cells for metastasis initiation. Cancer Cell.22:571-584. http://dx.doi.org/ 10.1016/j.ccr.2012.08.013

Campbell, I., K. Polyak, and I. Haviv. 2009. Clonal mutations in the cancerassociated fibroblasts: the case against genetic coevolution. Cancer Res. 69:6765-6768. http://dx.doi.org/10.1158/0008-5472.CAN-08-4253

Cardone, A., A. Tolino, R. Zarcone, G. Borruto Caracciolo, and E. Tartaglia. 1997. Prognostic value of desmoplastic reaction and lymphocytic infiltration in the management of breast cancer. Panminerva Med. 39:174-177.

Chaffer, C.L., and R.A.Weinberg. 2011. A perspective on cancer cell metastasis. Science. 331:1559-1564. http://dx.doi.org/10.1126/science.1203543

Chang, C.C., W.H. Hsu, C.C. Wang, C.H. Chou, M.Y. Kuo, B.R. Lin, S.T Chen, S.K.Tai, M.L. Kuo, and M.H.Yang. 2013. Connective tissue growth factor activates pluripotency genes and mesenchymal-epithelial transition in head and neck cancer cells. Cancer Res. 73:4147-4157. http://dx .doi.org/10.1158/0008-5472.CAN-12-4085

Chapman, P.B., A. Hauschild, C. Robert, J.B. Haanen, P. Ascierto, J. Larkin, R. Dummer, C. Garbe, A. Testori, M. Maio, et al. BRIM-3 Study Group. 2011. Improved survival with vemurafenib in melanoma with BRAF V600E mutation. N. Engl. J. Med. 364:2507-2516. http:// dx.doi.org/10.1056/NEJMoa1103782

Charrier, A., and D.R. Brigstock. 2013. Regulation of pancreatic function by connective tissue growth factor (CTGF, CCN2). Cytokine Growth Factor Rev. 24:59-68. http://dx.doi.org/10.1016/j.cytogfr.2012.07.001

Chaudhri,V.K., G.G. Salzler, S.A. Dick, M.S. Buckman, R. Sordella, E.D. Karoly, R. Mohney, B.M. Stiles, O. Elemento, N.K. Altorki, and T.E. McGraw. 2013. Metabolic alterations in lung cancer-associated fibroblasts correlated with increased glycolytic metabolism of the tumor. Mol. Cancer Res. 11:579-592. http://dx.doi.org/10.1158/1541-7786.MCR-12-0437-T

Chauhan, V.P., J.D. Martin, H. Liu, D.A. Lacorre, S.R. Jain, S.V. Kozin, T. Stylianopoulos, A.S. Mousa, X. Han, P. Adstamongkonkul, et al. 2013. Angiotensin inhibition enhances drug delivery and potentiates chemotherapy by decompressing tumour blood vessels. Nat. Commun. 4:2516. http://dx.doi.org/10.1038/ncomms3516

Cheng, J., Y. Wang, A. Liang, L. Jia, and J. Du. 2012. FSP-1 silencing in bone marrow cells suppresses neointima formation in vein graft. Circ. Res. 110:230-240. http://dx.doi.org/10.1161/CIRCRESAHA.111.246025 
Cheng, J.D., M. Valianou, A.A. Canutescu, E.K. Jaffe, H.O. Lee, H. Wang, J.H. Lai, W.W. Bachovchin, and L.M. Weiner. 2005. Abrogation of fibroblast activation protein enzymatic activity attenuates tumor growth. Mol. Cancer Ther. 4:351-360.

Cho, J.A., H. Park, E.H. Lim, and K.W. Lee. 2012. Exosomes from breast cancer cells can convert adipose tissue-derived mesenchymal stem cells into myofibroblast-like cells. Int. J. Oncol. 40:130-138.

Choi, J., H. Kim, W.H. Jung, and J.S. Koo. 2013. Metabolic interaction between cancer cells and stromal cells according to breast cancer molecular subtype. Breast Cancer Res. 15:R78. http://dx.doi.org/10.1186/ bcr3472

Cirri, P., and P. Chiarugi. 2011. Cancer associated fibroblasts: the dark side of the coin. Am J Cancer Res. 1:482-497.

Cordes, N., J. Seidler, R. Durzok, H. Geinitz, and C. Brakebusch. 2006. $\beta 1$-integrin-mediated signaling essentially contributes to cell survival after radiation-induced genotoxic injury. Oncogene. 25:1378-1390. http:// dx.doi.org/10.1038/sj.onc.1209164

Crawford, Y., I. Kasman, L. Yu, C. Zhong, X. Wu, Z. Modrusan, J. Kaminker, and N. Ferrara. 2009. PDGF-C mediates the angiogenic and tumorigenic properties of fibroblasts associated with tumors refractory to anti-VEGF treatment. Cancer Cell. 15:21-34. http://dx.doi.org/10 $.1016 /$ j.ccr.2008.12.004

Cukierman, E., and D.E. Bassi. 2010. Physico-mechanical aspects of extracellular matrix influences on tumorigenic behaviors. Semin. Cancer Biol. 20:139-145. http://dx.doi.org/10.1016/j.semcancer.2010.04.004

Cuttler, A.S., R.J. LeClair, J.P. Stohn, Q. Wang, C.M. Sorenson, L. Liaw, and V. Lindner. 2011. Characterization of Pdgfrb-Cre transgenic mice reveals reduction of ROSA26 reporter activity in remodeling arteries. Genesis. 49:673-680. http://dx.doi.org/10.1002/dvg.20769

Danø, K., N. Behrendt, G. Høyer-Hansen, M. Johnsen, L.R. Lund, M. Ploug, and J. Rømer. 2005. Plasminogen activation and cancer. Thromb. Haemost. 93:676-681.

Desmoulière, A., M. Redard, I. Darby, and G. Gabbiani. 1995. Apoptosis mediates the decrease in cellularity during the transition between granulation tissue and scar. Am. J. Pathol. 146:56-66.

Desmoulière,A., C. Guyot, and G. Gabbiani. 2004. The stroma reaction myofibroblast: a key player in the control of tumor cell behavior. Int. J. Dev. Biol. 48:509-517. http://dx.doi.org/10.1387/ijdb.041802ad

Ding, N., R.T.Yu, N. Subramaniam, M.H. Sherman, C. Wilson, R. Rao, M. Leblanc, S. Coulter, M. He, C. Scott, et al. 2013. A vitamin D receptor/ SMAD genomic circuit gates hepatic fibrotic response. Cell. 153:601613. http://dx.doi.org/10.1016/j.cell.2013.03.028

Diop-Frimpong, B., V.P. Chauhan, S. Krane, Y. Boucher, and R.K. Jain. 2011 Losartan inhibits collagen I synthesis and improves the distribution and efficacy of nanotherapeutics in tumors. Proc. Natl. Acad. Sci. USA 108:2909-2914. http://dx.doi.org/10.1073/pnas.1018892108

Direkze, N.C., K. Hodivala-Dilke, R. Jeffery, T. Hunt, R. Poulsom, D. Oukrif, M.R. Alison, and N.A. Wright. 2004. Bone marrow contribution to tumor-associated myofibroblasts and fibroblasts. Cancer Res. 64:84928495. http://dx.doi.org/10.1158/0008-5472.CAN-04-1708

Doherty, J.R., and J.L. Cleveland. 2013. Targeting lactate metabolism for cancer therapeutics. J. Clin. Invest. 123:3685-3692. http://dx.doi.org/ 10.1172/JCI69741

Domanska, U.M., H. Timmer-Bosscha, W.B. Nagengast, T.H. Oude Munnink, R.C. Kruizinga, H.J. Ananias, N.M. Kliphuis, G. Huls, E.G. De Vries, I.J. de Jong, and A.M. Walenkamp. 2012. CXCR4 inhibition with AMD3100 sensitizes prostate cancer to docetaxel chemotherapy. Neoplasia. 14:709-718.

Duda, D.G., A.M. Duyverman, M. Kohno, M. Snuderl, E.J. Steller, D. Fukumura, and R.K. Jain. 2010. Malignant cells facilitate lung metastasis by bringing their own soil. Proc. Natl. Acad. Sci. USA. 107:2167721682. http://dx.doi.org/10.1073/pnas.1016234107

Dufour, A., and C.M. Overall. 2013. Missing the target: matrix metalloproteinase antitargets in inflammation and cancer. Trends Pharmacol. Sci. 34:233-242. http://dx.doi.org/10.1016/j.tips.2013.02.004

Dvorak, H.F. 1986. Tumors: wounds that do not heal. Similarities between tumor stroma generation and wound healing. N. Engl. J. Med. 315:1650-1659. http://dx.doi.org/10.1056/NEJM198612253152606
Eguchi, D., N. Ikenaga, K. Ohuchida, S. Kozono, L. Cui, K. Fujiwara, M. Fujino, T. Ohtsuka, K. Mizumoto, and M. Tanaka. 2013. Hypoxia enhances the interaction between pancreatic stellate cells and cancer cells via increased secretion of connective tissue growth factor. J. Surg. Res. 181:225-233. http://dx.doi.org/10.1016/j.jss.2012.06.051

Erez, N., M. Truitt, P. Olson, S.T. Arron, and D. Hanahan. 2010. CancerAssociated Fibroblasts Are Activated in Incipient Neoplasia to Orchestrate Tumor-Promoting Inflammation in an NF-kB-Dependent Manner. Cancer Cell. 17:135-147. http://dx.doi.org/10.1016/j.ccr.2009.12.041

Erkan, M., C.W. Michalski, S. Rieder, C. Reiser-Erkan, I. Abiatari, A Kolb, N.A. Giese, I. Esposito, H. Friess, and J. Kleeff. 2008. The activated stroma index is a novel and independent prognostic marker in pancreatic ductal adenocarcinoma. Clin. Gastroenterol. Hepatol. 6:11551161. http://dx.doi.org/10.1016/j.cgh.2008.05.006

Erler, J.T., and V.M. Weaver. 2009. Three-dimensional context regulation of metastasis. Clin. Exp. Metastasis. 26:35-49. http://dx.doi.org/10 .1007/s10585-008-9209-8

Farmer, P., H. Bonnefoi, P. Anderle, D. Cameron, P. Wirapati, V. Becette, S. André, M. Piccart, M. Campone, E. Brain, et al. 2009. A stroma-related gene signature predicts resistance to neoadjuvant chemotherapy in breast cancer. Nat. Med. 15:68-74. http://dx.doi.org/10.1038/nm.1908

Feig, C., J.O. Jones, M. Kraman, R.J. Wells, A. Deonarine, D.S. Chan, C.M. Connell, E.W. Roberts, Q. Zhao, O.L. Caballero, et al. 2013. Targeting CXCL12 from FAP-expressing carcinoma-associated fibroblasts synergizes with anti-PD-L1 immunotherapy in pancreatic cancer. Proc. Natl.Acad. Sci. USA.110:20212-20217. http://dx.doi.org/10.1073/pnas .1320318110

Fidler, I.J., C. Wilmanns, A. Staroselsky, R. Radinsky, Z. Dong, and D. Fan. 1994. Modulation of tumor cell response to chemotherapy by the organ environment. Cancer Metastasis Rev. 13:209-222. http://dx.doi.org/ 10.1007/BF00689637

Flaberg, E., L. Markasz, G. Petranyi, G. Stuber, F. Dicso, N. Alchihabi, È. Oláh, I. Csízy, T. Józsa, O. Andrén, et al. 2011. High-throughput livecell imaging reveals differential inhibition of tumor cell proliferation by human fibroblasts. Int. J. Cancer. 128:2793-2802. http://dx.doi.org/ $10.1002 /$ ijc. 25612

Flaherty, K.T., I. Puzanov, K.B. Kim, A. Ribas, G.A. McArthur, J.A. Sosman, P.J. O’Dwyer, R.J. Lee, J.F. Grippo, K. Nolop, and P.B. Chapman. 2010. Inhibition of mutated, activated BRAF in metastatic melanoma. N. Engl. J. Med. 363:809-819. http://dx.doi.org/10.1056/NEJMoa1002011

Forsberg, K., I. Valyi-Nagy, C.H. Heldin, M. Herlyn, and B. Westermark. 1993. Platelet-derived growth factor (PDGF) in oncogenesis: development of a vascular connective tissue stroma in xenotransplanted human melanoma producing PDGF-BB. Proc. Natl. Acad. Sci. USA. 90:393397. http://dx.doi.org/10.1073/pnas.90.2.393

Frese, K.K., A. Neesse, N. Cook, T.E. Bapiro, M.P. Lolkema, D.I. Jodrell, and D.A. Tuveson. 2012. nab-Paclitaxel potentiates gemcitabine activity by reducing cytidine deaminase levels in a mouse model of pancreatic cancer. Cancer Discov. 2:260-269. http://dx.doi.org/10.1158/2159-8290 .CD-11-0242

Fridman, R., G. Giaccone, T. Kanemoto, G.R. Martin, A.F. Gazdar, and J.L. Mulshine. 1990. Reconstituted basement membrane (matrigel) and laminin can enhance the tumorigenicity and the drug resistance of small cell lung cancer cell lines. Proc. Natl. Acad. Sci. USA. 87:6698-6702. http://dx.doi.org/10.1073/pnas.87.17.6698

Froeling, F.E., C. Feig, C. Chelala, R. Dobson, C.E. Mein, D.A. Tuveson, H. Clevers, I.R. Hart, and H.M. Kocher. 2011. Retinoic acid-induced pancreatic stellate cell quiescence reduces paracrine Wnt- $\beta$-catenin signaling to slow tumor progression. Gastroenterology. 141:1486-1497: 1497.e14. http://dx.doi.org/10.1053/j.gastro.2011.06.047

Gaggioli, C., S. Hooper, C. Hidalgo-Carcedo, R. Grosse, J.F. Marshall, K. Harrington, and E. Sahai. 2007. Fibroblast-led collective invasion of carcinoma cells with differing roles for RhoGTPases in leading and following cells. Nat. Cell Biol. 9:1392-1400. http://dx.doi.org/10.1038/ncb1658

Gao, R., and D.R. Brigstock. 2005. Connective tissue growth factor (CCN2) in rat pancreatic stellate cell function: integrin $\alpha_{5} \beta_{1}$ as a novel CCN2 receptor. Gastroenterology. 129:1019-1030. http://dx.doi.org/10.1053/ j.gastro.2005.06.067 
Garin-Chesa, P., L.J. Old, and W.J. Rettig. 1990. Cell surface glycoprotein of reactive stromal fibroblasts as a potential antibody target in human epithelial cancers. Proc. Natl. Acad. Sci. USA. 87:7235-7239. http://dx .doi.org/10.1073/pnas.87.18.7235

Giannoni, E., F. Bianchini, L. Masieri, S. Serni, E. Torre, L. Calorini, and P. Chiarugi. 2010. Reciprocal activation of prostate cancer cells and cancer-associated fibroblasts stimulates epithelial-mesenchymal transition and cancer stemness. Cancer Res. 70:6945-6956. http://dx.doi.org/10 .1158/0008-5472.CAN-10-0785

Giannoni, E., F. Bianchini, L. Calorini, and P. Chiarugi. 2011. Cancer associated fibroblasts exploit reactive oxygen species through a proinflammatory signature leading to epithelial mesenchymal transition and stemness. Antioxid. Redox Signal. 14:2361-2371. http://dx.doi.org/10.1089/ars .2010 .3727

Goetz, J.G., S. Minguet, I. Navarro-Lérida, J.J. Lazcano, R. Samaniego, E. Calvo, M. Tello, T. Osteso-Ibáñez, T. Pellinen, A. Echarri, et al. 2011. Biomechanical remodeling of the microenvironment by stromal caveolin-1 favors tumor invasion and metastasis. Cell. 146:148-163. http:// dx.doi.org/10.1016/j.cell.2011.05.040

Gonda, T.A., A.Varro, T.C. Wang, and B. Tycko. 2010. Molecular biology of cancer-associated fibroblasts: can these cells be targeted in anti-cancer therapy? Semin. Cell Dev. Biol. 21:2-10. http://dx.doi.org/10.1016/ j.semcdb.2009.10.001

Götte, M., and G.W. Yip. 2006. Heparanase, hyaluronan, and CD44 in cancers: a breast carcinoma perspective. Cancer Res. 66:10233-10237. http://dx.doi.org/10.1158/0008-5472.CAN-06-1464

Grivennikov, S.I., F.R. Greten, and M. Karin. 2010. Immunity, inflammation, and cancer. Cell. 140:883-899. http://dx.doi.org/10.1016/j.cell 2010.01 .025

Grum-Schwensen,B.,J.Klingelhofer, C.H.Berg, C.El-Naaman, M. Grigorian, E. Lukanidin, and N. Ambartsumian. 2005. Suppression of tumor development and metastasis formation in mice lacking the S100A4(mts1) gene. Cancer Res. 65:3772-3780. http://dx.doi.org/10.1158/0008-5472 .CAN-04-4510

Gu, J., H. Qian, L. Shen, X. Zhang, W. Zhu, L. Huang, Y. Yan, F. Mao, C. Zhao, Y. Shi, and W. Xu. 2012. Gastric cancer exosomes trigger differentiation of umbilical cord derived mesenchymal stem cells to carcinoma-associated fibroblasts through TGF- $\beta /$ Smad pathway. PLoS ONE. 7:e52465. http://dx.doi.org/10.1371/journal.pone.0052465

Guarino, M., B. Rubino, and G. Ballabio. 2007. The role of epithelialmesenchymal transition in cancer pathology. Pathology. 39:305-318. http://dx.doi.org/10.1080/00313020701329914

Guerra, C., A.J. Schuhmacher, M. Cañamero, P.J. Grippo, L. Verdaguer, L. Pérez-Gallego, P. Dubus, E.P. Sandgren, and M. Barbacid. 2007. Chronic pancreatitis is essential for induction of pancreatic ductal adenocarcinoma by K-Ras oncogenes in adult mice. Cancer Cell. 11:291302. http://dx.doi.org/10.1016/j.ccr.2007.01.012

Guido, C., D. Whitaker-Menezes, C. Capparelli, R. Balliet, Z. Lin, R.G. Pestell, A. Howell, S. Aquila, S. Andò, U. Martinez-Outschoorn, et al. 2012. Metabolic reprogramming of cancer-associated fibroblasts by TGF- $\beta$ drives tumor growth: connecting TGF- $\beta$ signaling with "Warburg-like" cancer metabolism and L-lactate production. Cell Cycle. 11:3019-3035. http://dx.doi.org/10.4161/cc.21384

Guo, X., H. Oshima, T. Kitmura, M.M. Taketo, and M. Oshima. 2008. Stromal fibroblasts activated by tumor cells promote angiogenesis in mouse gastric cancer.J. Biol. Chem. 283:19864-19871. http://dx.doi.org/ 10.1074/jbc.M800798200

Hamada, S., A. Masamune, T. Takikawa, N. Suzuki, K. Kikuta, M. Hirota, H. Hamada, M. Kobune, K. Satoh, and T. Shimosegawa. 2012 Pancreatic stellate cells enhance stem cell-like phenotypes in pancreatic cancer cells. Biochem. Biophys. Res. Commun. 421:349-354. http:// dx.doi.org/10.1016/j.bbrc.2012.04.014

Hanahan, D., and R.A. Weinberg. 2011. Hallmarks of cancer: the next generation. Cell. 144:646-674. http://dx.doi.org/10.1016/j.cell.2011.02.013

Hartel, M., F.F. Di Mola, A. Gardini, A. Zimmermann, P. Di Sebastiano, A. Guweidhi, P. Innocenti, T. Giese, N. Giese, M.W. Büchler, and H. Friess. 2004. Desmoplastic reaction influences pancreatic cancer growth behavior. World J. Surg. 28:818-825. http://dx.doi.org/10.1007/ s00268-004-7147-4
Hartmann, T.N., J.A. Burger, A. Glodek, N. Fujii, and M. Burger. 2005. CXCR 4 chemokine receptor and integrin signaling co-operate in mediating adhesion and chemoresistance in small cell lung cancer (SCLC) cells. Oncogene. 24:4462-4471. http://dx.doi.org/10.1038/sj.onc.1208621

Haubeiss, S., J.O. Schmid, T.E. Mürdter, M. Sonnenberg, G. Friedel, H. van der Kuip, and W.E. Aulitzky. 2010. Dasatinib reverses cancerassociated fibroblasts (CAFs) from primary lung carcinomas to a phenotype comparable to that of normal fibroblasts. Mol. Cancer. 9:168. http://dx.doi.org/10.1186/1476-4598-9-168

Hawinkels, L.J., M. Paauwe, H.W. Verspaget, E. Wiercinska, J.M. van der Zon, K. van der Ploeg, P.J. Koelink, J.H. Lindeman, W. Mesker, P. ten Dijke, and C.F. Sier. 2014. Interaction with colon cancer cells hyperactivates TGF- $\beta$ signaling in cancer-associated fibroblasts. Oncogene. 33:97-107. http://dx.doi.org/10.1038/onc.2012.536

Hayward, S.W., Y. Wang, M. Cao, Y.K. Hom, B. Zhang, G.D. Grossfeld, D. Sudilovsky, and G.R. Cunha. 2001. Malignant transformation in a nontumorigenic human prostatic epithelial cell line. Cancer Res. 61:8135-8142.

Herrera, M., A.B. Islam, A. Herrera, P. Martín, V. García, J. Silva, J.M. Garcia, C. Salas, I. Casal, A.G. de Herreros, et al. 2013. Functional heterogeneity of cancer-associated fibroblasts from human colon tumors shows specific prognostic gene expression signature. Clin. Cancer Res. 19:5914-5926. http://dx.doi.org/10.1158/1078-0432.CCR-13-0694

Hill, R., Y. Song, R.D. Cardiff, and T. Van Dyke. 2005. Selective evolution of stromal mesenchyme with $\mathrm{p} 53$ loss in response to epithelial tumorigenesis. Cell. 123:1001-1011. http://dx.doi.org/10.1016/j.cell.2005.09.030

Hinz, B., G. Celetta, J.J. Tomasek, G. Gabbiani, and C. Chaponnier. 2001. Alpha-smooth muscle actin expression upregulates fibroblast contractile activity. Mol. Biol. Cell. 12:2730-2741. http://dx.doi.org/10.1091/ mbc.12.9.2730

Hofheinz, R.D., S.E. al-Batran, F. Hartmann, G. Hartung, D. Jäger, C. Renner, P. Tanswell, U. Kunz, A. Amelsberg, H. Kuthan, and G. Stehle. 2003. Stromal antigen targeting by a humanised monoclonal antibody: an early phase II trial of sibrotuzumab in patients with metastatic colorectal cancer. Onkologie. 26:44-48. http://dx.doi.org/10.1159/000069863

Hooper, S., C. Gaggioli, and E. Sahai. 2010. A chemical biology screen reveals a role for Rab21-mediated control of actomyosin contractility in fibroblast-driven cancer invasion. Br. J. Cancer. 102:392-402. http:// dx.doi.org/10.1038/sj.bjc.6605469

Hosein, A.N., M. Wu, S.L. Arcand, S. Lavallée, J. Hébert, P.N. Tonin, and M. Basik. 2010. Breast carcinoma-associated fibroblasts rarely contain p53 mutations or chromosomal aberrations. Cancer Res. 70:5770-5777. http://dx.doi.org/10.1158/0008-5472.CAN-10-0673

Hu, M., J. Yao, L. Cai, K.E. Bachman, F. van den Brûle, V. Velculescu, and K. Polyak. 2005. Distinct epigenetic changes in the stromal cells of breast cancers. Nat. Genet. 37:899-905. http://dx.doi.org/10.1038/ng1596

Hu, M., G. Peluffo, H. Chen, R. Gelman, S. Schnitt, and K. Polyak. 2009. Role of COX-2 in epithelial-stromal cell interactions and progression of ductal carcinoma in situ of the breast. Proc. Natl. Acad. Sci. USA. 106:3372-3377. http://dx.doi.org/10.1073/pnas.0813306106

Huang, S., R. Fang,J.Xu,S. Qiu, H.Zhang,J.Du, and S. Cai.2011.Evaluation of the tumor targeting of a FAP $\alpha$-based doxorubicin prodrug. J. Drug Target. 19:487-496. http://dx.doi.org/10.3109/1061186X.2010.511225

Hwang, R.F., T. Moore, T. Arumugam, V. Ramachandran, K.D. Amos, A. Rivera, B. Ji, D.B. Evans, and C.D. Logsdon. 2008. Cancerassociated stromal fibroblasts promote pancreatic tumor progression. CancerRes.68:918-926.http://dx.doi.org/10.1158/0008-5472.CAN07-5714

Iijima, J., K. Konno, and N. Itano. 2011. Inflammatory alterations of the extracellular matrix in the tumor microenvironment. Cancers (Basel) 3:3189-3205. http://dx.doi.org/10.3390/cancers3033189

Ishii, G., T. Sangai, T. Oda, Y. Aoyagi, T. Hasebe, N. Kanomata, Y. Endoh, C. Okumura,Y. Okuhara, J. Magae, et al. 2003. Bone-marrow-derived myofibroblasts contribute to the cancer-induced stromal reaction. Biochem. Biophys. Res. Commun. 309:232-240. http://dx.doi.org/10.1016/S0006291X(03)01544-4

Iwano, M., D. Plieth, T.M. Danoff, C. Xue, H. Okada, and E.G. Neilson. 2002. Evidence that fibroblasts derive from epithelium during tissue fibrosis.J. Clin. Invest. 110:341-350.http://dx.doi.org/10.1172/ JCI0215518 
Jacobetz, M.A., D.S. Chan, A. Neesse, T.E. Bapiro, N. Cook, K.K. Frese, C. Feig, T. Nakagawa, M.E. Caldwell, H.I. Zecchini, et al. 2013. Hyaluronan impairs vascular function and drug delivery in a mouse model of pancreatic cancer. Gut. 62:112-120. http://dx.doi .org/10.1136/gutjnl-2012-302529

Jacobson, A., and J.L. Cunningham. 2012. Connective tissue growth factor in tumor pathogenesis. Fibrogenesis Tissue Repair. 5:S8. http://dx.doi .org/10.1186/1755-1536-5-S1-S8

Jain, R.K. 1990. Vascular and interstitial barriers to delivery of therapeutic agents in tumors. Cancer Metastasis Rev. 9:253-266. http://dx.doi .org/10.1007/BF00046364

Jedeszko, C., B.C. Victor, I. Podgorski, and B.F. Sloane. 2009. Fibroblast hepatocyte growth factor promotes invasion of human mammary ductal carcinoma in situ. Cancer Res. 69:9148-9155. http://dx.doi .org/10.1158/0008-5472.CAN-09-1043

Jeon, E.S., H.J. Moon, M.J. Lee, H.Y. Song, Y.M. Kim, M. Cho, D.S. Suh, M.S. Yoon, C.L. Chang, J.S. Jung, and J.H. Kim. 2008. Cancer-derived lysophosphatidic acid stimulates differentiation of human mesenchymal stem cells to myofibroblast-like cells. Stem Cells. 26:789-797. http:// dx.doi.org/10.1634/stemcells.2007-0742

Jiang, L., T.A. Gonda, M.V. Gamble, M. Salas, V. Seshan, S. Tu, W.S. Twaddell, P. Hegyi, G. Lazar, I. Steele, et al. 2008. Global hypomethylation of genomic DNA in cancer-associated myofibroblasts. Cancer Res. 68:9900-9908. http://dx.doi.org/10.1158/0008-5472.CAN08-1319

Jung, D.W., Z.M. Che, J. Kim, K. Kim, K.Y. Kim, D. Williams, and J. Kim. 2010. Tumor-stromal crosstalk in invasion of oral squamous cell carcinoma: a pivotal role of CCL7. Int. J. Cancer. 127:332-344.

Kadaba, R., H. Birke, J. Wang, S. Hooper, C.D. Andl, F. Di Maggio, E. Soylu, M. Ghallab, D. Bor, F.E. Froeling, et al. 2013. Imbalance of desmoplastic stromal cell numbers drives aggressive cancer processes. J. Pathol. 230:107-117. http://dx.doi.org/10.1002/path.4172

Kahlert, C., and R. Kalluri. 2013. Exosomes in tumor microenvironment influence cancer progression and metastasis. J. Mol. Med. 91:431-437. http://dx.doi.org/10.1007/s00109-013-1020-6

Kalluri, R., and M. Zeisberg. 2006. Fibroblasts in cancer. Nat. Rev. Cancer. 6:392-401. http://dx.doi.org/10.1038/nrc1877

Kano, M.R., Y. Bae, C. Iwata, Y. Morishita, M. Yashiro, M. Oka, T. Fujii, A. Komuro, K. Kiyono, M. Kaminishi, et al. 2007. Improvement of cancer-targeting therapy, using nanocarriers for intractable solid tumors by inhibition of TGF- $\beta$ signaling. Proc. Natl. Acad. Sci. USA. 104:34603465. http://dx.doi.org/10.1073/pnas.0611660104

Karnoub, A.E., A.B. Dash, A.P. Vo, A. Sullivan, M.W. Brooks, G.W. Bell, A.L. Richardson, K. Polyak, R. Tubo, and R.A. Weinberg. 2007. Mesenchymal stem cells within tumour stroma promote breast cancer metastasis. Nature. 449:557-563. http://dx.doi.org/10.1038/nature06188

Kawase, A., G. Ishii, K. Nagai, T. Ito, T. Nagano, Y. Murata, T. Hishida, M. Nishimura, J. Yoshida, K. Suzuki, and A. Ochiai. 2008. Podoplanin expression by cancer associated fibroblasts predicts poor prognosis of lung adenocarcinoma. Int. J. Cancer. 123:1053-1059. http://dx.doi.org/ $10.1002 / \mathrm{ijc} .23611$

Kidd, S., E. Spaeth, K. Watson, J. Burks, H. Lu, A. Klopp, M. Andreeff, and F.C. Marini. 2012. Origins of the tumor microenvironment: quantitative assessment of adipose-derived and bone marrow-derived stroma. PLoS ONE. 7:e30563. http://dx.doi.org/10.1371/journal.pone.0030563

Kikuta, K., A. Masamune, T. Watanabe, H. Ariga, H. Itoh, S. Hamada, K Satoh, S. Egawa, M. Unno, and T. Shimosegawa. 2010. Pancreatic stellate cells promote epithelial-mesenchymal transition in pancreatic cancer cells. Biochem. Biophys. Res. Commun. 403:380-384. http://dx.doi.org/10 .1016/j.bbrc.2010.11.040

Kinugasa, Y., T. Matsui, and N. Takakura. 2014. CD44 expressed on cancerassociated fibroblasts is a functional molecule supporting the stemness and drug resistance of malignant cancer cells in the tumor microenvironment. Stem Cells. 32:145-156. http://dx.doi.org/10.1002/stem.1556

Kobayashi, N., S. Miyoshi, T. Mikami, H. Koyama, M. Kitazawa, M. Takeoka, K. Sano, J. Amano, Z. Isogai, S. Niida, et al. 2010. Hyaluronan deficiency in tumor stroma impairs macrophage trafficking and tumor neovascularization. Cancer Res. 70:7073-7083. http://dx.doi.org/10.1158/00085472.CAN-09-4687
Kojima, Y., A. Acar, E.N. Eaton, K.T. Mellody, C. Scheel, I. Ben-Porath, T.T. Onder, Z.C. Wang, A.L. Richardson, R.A. Weinberg, and A. Orimo. 2010. Autocrine TGF- $\beta$ and stromal cell-derived factor-1 (SDF-1) signaling drives the evolution of tumor-promoting mammary stromal myofibroblasts. Proc. Natl. Acad. Sci. USA. 107:20009-20014. http://dx.doi.org/10.1073/pnas.1013805107

Kordes, C., I. Sawitza, and D. Häussinger. 2009. Hepatic and pancreatic stellate cells in focus. Biol. Chem. 390:1003-1012. http://dx.doi.org/ 10.1515/BC.2009.121

Koukourakis, M.I., A. Giatromanolaki, A.L. Harris, and E. Sivridis. 2006. Comparison of metabolic pathways between cancer cells and stromal cells in colorectal carcinomas: a metabolic survival role for tumor-associated stroma. Cancer Res. 66:632-637. http://dx.doi.org/10.1158/00085472.CAN-05-3260

Kraman, M., P.J. Bambrough, J.N. Arnold, E.W. Roberts, L. Magiera, J.O. Jones, A. Gopinathan, D.A. Tuveson, and D.T. Fearon. 2010. Suppression of antitumor immunity by stromal cells expressing fibroblast activation protein- $\alpha$. Science. 330:827-830. http://dx.doi.org/10 $.1126 /$ science. 1195300

Krtolica, A., S. Parrinello, S. Lockett, P.Y. Desprez, and J. Campisi. 2001. Senescent fibroblasts promote epithelial cell growth and tumorigenesis: a link between cancer and aging. Proc. Natl. Acad. Sci. USA. 98:1207212077. http://dx.doi.org/10.1073/pnas. 211053698

Kuperwasser, C., T. Chavarria, M. Wu, G. Magrane, J.W. Gray, L. Carey, A. Richardson, and R.A. Weinberg. 2004. Reconstruction of functionally normal and malignant human breast tissues in mice. Proc. Natl. Acad. Sci. USA. 101:4966-4971. http://dx.doi.org/10.1073/pnas.0401064101

Kurose, K., K. Gilley, S. Matsumoto, P.H. Watson, X.P. Zhou, and C. Eng. 2002. Frequent somatic mutations in PTEN and TP53 are mutually exclusive in the stroma of breast carcinomas. Nat. Genet. 32:355-357. http://dx.doi.org/10.1038/ng1013

Kwabi-Addo, B., M. Ozen, and M. Ittmann. 2004. The role of fibroblast growth factors and their receptors in prostate cancer. Endocr. Relat. Cancer. 11:709-724. http://dx.doi.org/10.1677/erc.1.00535

LeBeau, A.M., W.N. Brennen, S. Aggarwal, and S.R. Denmeade. 2009. Targeting the cancer stroma with a fibroblast activation protein-activated promelittin protoxin. Mol. Cancer Ther. 8:1378-1386. http://dx.doi .org/10.1158/1535-7163.MCT-08-1170

Lederle, W., B. Hartenstein, A. Meides, H. Kunzelmann, Z. Werb, P. Angel, and M.M. Mueller. 2010. MMP13 as a stromal mediator in controlling persistent angiogenesis in skin carcinoma. Carcinogenesis. 31:1175-1184. http://dx.doi.org/10.1093/carcin/bgp248

Lee, J., M. Fassnacht, S. Nair, D. Boczkowski, and E. Gilboa. 2005. Tumor immunotherapy targeting fibroblast activation protein, a product expressed in tumor-associated fibroblasts. Cancer Res. 65:11156-11163. http://dx.doi.org/10.1158/0008-5472.CAN-05-2805

Lee, M.J., A.S. Ye, A.K. Gardino, A.M. Heijink, P.K. Sorger, G. MacBeath, and M.B. Yaffe. 2012. Sequential application of anticancer drugs enhances cell death by rewiring apoptotic signaling networks. Cell. 149:780-794. http://dx.doi.org/10.1016/j.cell.2012.03.031

Lemons, J.M., X.J. Feng, B.D. Bennett, A. Legesse-Miller, E.L. Johnson, I. Raitman, E.A. Pollina, H.A. Rabitz, J.D. Rabinowitz, and H.A. Coller. 2010. Quiescent fibroblasts exhibit high metabolic activity. PLoS Biol. 8:e1000514. http://dx.doi.org/10.1371/journal.pbio.1000514

Levental, K.R., H. Yu, L. Kass, J.N. Lakins, M. Egeblad, J.T. Erler, S.F. Fong, K. Csiszar, A. Giaccia, W. Weninger, et al. 2009. Matrix crosslinking forces tumor progression by enhancing integrin signaling. Cell. 139:891-906. http://dx.doi.org/10.1016/j.cell.2009.10.027

Li, H.J., F. Reinhardt, H.R. Herschman, and R.A. Weinberg. 2012a. Cancer-stimulated mesenchymal stem cells create a carcinoma stem cell niche via prostaglandin E2 signaling. Cancer Discov. 2:840-855. http:// dx.doi.org/10.1158/2159-8290.CD-12-0101

Li, T., Y. Yang, X. Hua, G. Wang, W. Liu, C. Jia, Y. Tai, Q. Zhang, and G. Chen. 2012b. Hepatocellular carcinoma-associated fibroblasts trigger NK cell dysfunction via PGE2 and IDO. Cancer Lett. 318:154-161. http://dx.doi.org/10.1016/j.canlet.2011.12.020

Li, X., Q. Ma, Q. Xu, H. Liu, J. Lei, W. Duan, K. Bhat, F. Wang, E. Wu, and Z. Wang. 2012c. SDF-1/CXCR4 signaling induces pancreatic cancer cell invasion and epithelial-mesenchymal transition in vitro 
through non-canonical activation of Hedgehog pathway. Cancer Lett. 322:169-176. http://dx.doi.org/10.1016/j.canlet.2012.02.035

Liao, D., Y. Luo, D. Markowitz, R. Xiang, and R.A. Reisfeld. 2009. Cancer associated fibroblasts promote tumor growth and metastasis by modulating the tumor immune microenvironment in a 4T1 murine breast cancer model. PLoS ONE. 4:e7965. http://dx.doi.org/10.1371/ journal.pone. 0007965

Lieubeau, B., L. Garrigue, I. Barbieux, K. Meflah, and M. Gregoire. 1994. The role of transforming growth factor beta 1 in the fibroblastic reaction associated with rat colorectal tumor development. Cancer Res. 54:6526-6532.

Liu, J., S. Liao, B. Diop-Frimpong, W. Chen, S. Goel, K. Naxerova, M. Ancukiewicz, Y. Boucher, R.K. Jain, and L. Xu. 2012. TGF- $\beta$ blockade improves the distribution and efficacy of therapeutics in breast carcinoma by normalizing the tumor stroma. Proc. Natl. Acad. Sci. USA. 109:16618-16623. http://dx.doi.org/10.1073/pnas.1117610109

Liu, S., C. Ginestier, S.J. Ou, S.G. Clouthier, S.H. Patel, F. Monville, H. Korkaya, A. Heath, J. Dutcher, C.G. Kleer, et al. 2011. Breast cancer stem cells are regulated by mesenchymal stem cells through cytokine networks. Cancer Res. 71:614-624. http://dx.doi.org/10.1158/00085472.CAN-10-0538

Loeffler, M., J.A. Krüger, A.G. Niethammer, and R.A. Reisfeld. 2006. Targeting tumor-associated fibroblasts improves cancer chemotherapy by increasing intratumoral drug uptake. J. Clin. Invest. 116:1955-1962. http://dx.doi.org/10.1172/JCI26532

Löhr, M., C. Schmidt, J. Ringel, M. Kluth, P. Müller, H. Nizze, and R. Jesnowski. 2001. Transforming growth factor-beta1 induces desmoplasia in an experimental model of human pancreatic carcinoma. Cancer Res. 61:550-555.

Lotti, F., A.M. Jarrar, R.K. Pai, M. Hitomi, J. Lathia, A. Mace, G.A. Gantt Jr., K. Sukhdeo, J. DeVecchio, A. Vasanji, et al. 2013. Chemotherapy activates cancer-associated fibroblasts to maintain colorectal cancerinitiating cells by IL-17A. J. Exp. Med. 210:2851-2872. http://dx.doi.org/ 10.1084/jem.20131195

Luga, V., L. Zhang, A.M. Viloria-Petit, A.A. Ogunjimi, M.R. Inanlou, E. Chiu, M. Buchanan, A.N. Hosein, M. Basik, and J.L. Wrana. 2012. Exosomes mediate stromal mobilization of autocrine Wnt-PCP signaling in breast cancer cell migration. Cell. 151:1542-1556. http://dx.doi .org/10.1016/j.cell.2012.11.024

Mace, T.A., Z. Ameen, A. Collins, S. Wojcik, M. Mair, G.S. Young, J.R. Fuchs, T.D. Eubank, W.L. Frankel, T. Bekaii-Saab, et al. 2013. Pancreatic cancer-associated stellate cells promote differentiation of myeloid-derived suppressor cells in a STAT3-dependent manner. Cancer Res. 73:3007-3018. http://dx.doi.org/10.1158/0008-5472.CAN$12-4601$

Madar, S., R. Brosh, Y. Buganim, O. Ezra, I. Goldstein, H. Solomon, I. Kogan, N. Goldfinger, H. Klocker, and V. Rotter. 2009. Modulated expression of WFDC1 during carcinogenesis and cellular senescence. Carcinogenesis. 30:20-27. http://dx.doi.org/10.1093/carcin/bgn232

Maeshima, A.M., T. Niki, A. Maeshima, T. Yamada, H. Kondo, and Y. Matsuno. 2002. Modified scar grade: a prognostic indicator in small peripheral lung adenocarcinoma. Cancer. 95:2546-2554. http://dx.doi .org/10.1002/cncr.11006

Malanchi, I., A. Santamaria-Martínez, E. Susanto, H. Peng, H.A. Lehr, J.F. Delaloye, and J. Huelsken. 2012. Interactions between cancer stem cells and their niche govern metastatic colonization. Nature. 481:85-89. http://dx.doi.org/10.1038/nature10694

Martinez-Outschoorn, U.E., Z. Lin, C. Trimmer, N. Flomenberg, C. Wang, S. Pavlides, R.G. Pestell, A. Howell, F. Sotgia, and M.P. Lisanti. 2011. Cancer cells metabolically "fertilize" the tumor microenvironment with hydrogen peroxide, driving the Warburg effect: implications for PET imaging of human tumors. Cell Cycle. 10:2504-2520. http:// dx.doi.org/10.4161/cc.10.15.16585

Masamune, A., S. Hamada, K. Kikuta, T. Takikawa, S. Miura, E. Nakano, and T. Shimosegawa. 2013. The angiotensin II type I receptor blocker olmesartan inhibits the growth of pancreatic cancer by targeting stellate cell activities in mice. Scand. J. Gastroenterol. 48:602-609. http://dx.doi .org/10.3109/00365521.2013.777776

Masamune, A., E. Nakano, S. Hamada, T. Takikawa, N. Yoshida, and T. Shimosegawa. 2014. Alteration of the microRNA expression profile during the activation of pancreatic stellate cells. Scand. J. Gastroenterol. 49:323-331. http://dx.doi.org/10.3109/00365521.2013.876447

Matsuda, Y., S. Kure, and T. Ishiwata. 2012. Nestin and other putative cancer stem cell markers in pancreatic cancer. Med. Mol. Morphol. 45:59-65. http://dx.doi.org/10.1007/s00795-012-0571-x

McMillin, D.W., J.M. Negri, and C.S. Mitsiades. 2013. The role of tumourstromal interactions in modifying drug response: challenges and opportunities. Nat. Rev. Drug Discov. 12:217-228. http://dx.doi.org/10 $.1038 / \operatorname{nrd} 3870$

Meads, M.B., R.A. Gatenby, and W.S. Dalton. 2009. Environmentmediated drug resistance: a major contributor to minimal residual disease. Nat. Rev. Cancer. 9:665-674. http://dx.doi.org/10.1038/nrc2714

Mishra, P.J., P.J. Mishra, R. Humeniuk, D.J. Medina, G. Alexe, J.P. Mesirov, S. Ganesan, J.W. Glod, and D. Banerjee. 2008. Carcinomaassociated fibroblast-like differentiation of human mesenchymal stem cells. Cancer Res. 68:4331-4339. http://dx.doi.org/10.1158/0008-5472 CAN-08-0943

Mitra, A.K., M. Zillhardt, Y. Hua, P. Tiwari, A.E. Murmann, M.E. Peter, and E. Lengyel. 2012. MicroRNAs reprogram normal fibroblasts into cancer-associated fibroblasts in ovarian cancer. Cancer Discov. 2:11001108. http://dx.doi.org/10.1158/2159-8290.CD-12-0206

Miyamoto, H., T. Murakami, K. Tsuchida, H. Sugino, H. Miyake, and S. Tashiro. 2004. Tumor-stroma interaction of human pancreatic cancer: acquired resistance to anticancer drugs and proliferation regulation is dependent on extracellular matrix proteins. Pancreas. 28:38-44. http:// dx.doi.org/10.1097/00006676-200401000-00006

Mullamitha, S.A., N.C. Ton, G.J. Parker, A. Jackson, P.J. Julyan, C. Roberts, G.A. Buonaccorsi, Y. Watson, K. Davies, S. Cheung, et al. 2007. Phase I evaluation of a fully human anti-alphav integrin monoclonal antibody (CNTO 95) in patients with advanced solid tumors. Clin. Cancer Res. 13:2128-2135. http://dx.doi.org/10.1158/1078-0432.CCR-06-2779

Muranen, T., L.M. Selfors, D.T. Worster, M.P. Iwanicki, L. Song, F.C. Morales, S. Gao, G.B. Mills, and J.S. Brugge. 2012. Inhibition of PI3K/ mTOR leads to adaptive resistance in matrix-attached cancer cells Cancer Cell. 21:227-239. http://dx.doi.org/10.1016/j.ccr.2011.12.024

Musumeci, M., V. Coppola, A. Addario, M. Patrizii, M. Maugeri-Saccà, L. Memeo, C. Colarossi, F. Francescangeli, M. Biffoni, D. Collura, et al. 2011. Control of tumor and microenvironment cross-talk by miR-15a and miR-16 in prostate cancer. Oncogene. 30:4231-4242. http://dx.doi.org/ 10.1038/onc.2011.140

Nakagawa, H., S. Liyanarachchi, R.V. Davuluri, H. Auer, E.W. Martin Jr., A. de la Chapelle, and W.L. Frankel. 2004. Role of cancer-associated stromal fibroblasts in metastatic colon cancer to the liver and their expression profiles. Oncogene. 23:7366-7377. http://dx.doi.org/10.1038/ sj.onc. 1208013

Nakai, Y., H. Isayama, H. Ijichi, T. Sasaki, N. Sasahira, K. Hirano, H. Kogure, K. Kawakubo, H. Yagioka, Y. Yashima, et al. 2010. Inhibition of renin-angiotensin system affects prognosis of advanced pancreatic cancer receiving gemcitabine. Br. J. Cancer. 103:1644-1648. http:// dx.doi.org/10.1038/sj.bjc.6605955

Neesse, A., P. Michl, K.K. Frese, C. Feig, N. Cook, M.A. Jacobetz, M.P. Lolkema, M. Buchholz, K.P. Olive, T.M. Gress, and D.A. Tuveson. 2011. Stromal biology and therapy in pancreatic cancer. Gut. 60:861868. http://dx.doi.org/10.1136/gut.2010.226092

Neesse, A., K.K. Frese, T.E. Bapiro, T. Nakagawa, M.D. Sternlicht, T.W. Seeley, C. Pilarsky, D.I. Jodrell, S.M. Spong, and D.A. Tuveson. 2013 CTGF antagonism with mAb FG-3019 enhances chemotherapy response without increasing drug delivery in murine ductal pancreas cancer. Proc. Natl. Acad. Sci. USA. 110:12325-12330. http://dx.doi.org/ $10.1073 /$ pnas. 1300415110

Neesse, A., K.K. Frese, D.S. Chan, T.E. Bapiro, W.J. Howat, F.M. Richards, V. Ellenrieder, D.I. Jodrell, and D.A. Tuveson. 2014. SPARC independent drug delivery and antitumour effects of nab-paclitaxel in genetically engineered mice. Gut. 63:974-983. http://dx.doi.org/ 10.1136/gutjnl-2013-305559

Noskova, V., S. Ahmadi, E. Asander, and B. Casslén. 2009. Ovarian cancer cells stimulate uPA gene expression in fibroblastic stromal cells via multiple paracrine and autocrine mechanisms. Gynecol. Oncol. 115:121126. http://dx.doi.org/10.1016/j.ygyno.2009.06.026 
O'Connell, J.T., H. Sugimoto, V.G. Cooke, B.A. MacDonald, A.I. Mehta, V.S. LeBleu, R. Dewar, R.M. Rocha, R.R. Brentani, M.B. Resnick, et al. 2011. VEGF-A and Tenascin-C produced by S100A4+ $4^{+}$stromal cells are important for metastatic colonization. Proc. Natl. Acad. Sci. USA. 108:16002-16007. http://dx.doi.org/10.1073/pnas.1109493108

Ohuchida, K., K. Mizumoto, M. Murakami, L.W. Qian, N. Sato, E. Nagai, K. Matsumoto, T. Nakamura, and M. Tanaka. 2004. Radiation to stromal fibroblasts increases invasiveness of pancreatic cancer cells through tumor-stromalinteractions. CancerRes.64:3215-3222.http://dx.doi.org/ 10.1158/0008-5472.CAN-03-2464

Okada, H., T.M. Danoff, R. Kalluri, and E.G. Neilson. 1997. Early role of Fsp1 in epithelial-mesenchymal transformation. Am. J. Physiol. 273:F563-F574.

Olive, K.P., M.A. Jacobetz, C.J. Davidson, A. Gopinathan, D. McIntyre, D. Honess, B. Madhu, M.A. Goldgraben, M.E. Caldwell, D. Allard, et al. 2009. Inhibition of Hedgehog signaling enhances delivery of chemotherapy in a mouse model of pancreatic cancer. Science. 324:1457-1461. http://dx.doi.org/10.1126/science. 1171362

Olumi, A.F., G.D. Grossfeld, S.W. Hayward, P.R. Carroll, T.D. Tlsty, and G.R. Cunha. 1999. Carcinoma-associated fibroblasts direct tumor progression of initiated human prostatic epithelium. Cancer Res. 59: 5002-5011.

Orimo, A., and R.A. Weinberg. 2007. Heterogeneity of stromal fibroblasts in tumors. Cancer Biol. Ther. 6:618-619. http://dx.doi.org/10.4161/ cbt.6.4.4255

Orimo, A., Y. Tomioka, Y. Shimizu, M. Sato, S. Oigawa, K. Kamata, Y. Nogi, S. Inoue, M. Takahashi, T. Hata, and M. Muramatsu. 2001. Cancer-associated myofibroblasts possess various factors to promote endometrial tumor progression. Clin. Cancer Res. 7:3097-3105.

Orimo, A., P.B. Gupta, D.C. Sgroi, F. Arenzana-Seisdedos, T. Delaunay, R. Naeem, V.J. Carey, A.L. Richardson, and R.A. Weinberg. 2005. Stromal fibroblasts present in invasive human breast carcinomas promote tumor growth and angiogenesis through elevated SDF-1/CXCL12 secretion. Cell. 121:335-348. http://dx.doi.org/10.1016/j.cell.2005.02.034

Ostermann, E., P. Garin-Chesa, K.H. Heider, M. Kalat, H. Lamche, C. Puri, D. Kerjaschki, W.J. Rettig, and G.R. Adolf. 2008. Effective immunoconjugate therapy in cancer models targeting a serine protease of tumor fibroblasts. Clin. Cancer Res. 14:4584-4592. http://dx.doi.org/10 .1158/1078-0432.CCR-07-5211

Österreicher, C.H., M. Penz-Österreicher, S.I. Grivennikov, M. Guma, E.K. Koltsova, C. Datz, R. Sasik, G. Hardiman, M. Karin, and D.A. Brenner. 2011. Fibroblast-specific protein 1 identifies an inflammatory subpopulation of macrophages in the liver. Proc. Natl. Acad. Sci. USA. 108:308-313. http://dx.doi.org/10.1073/pnas.1017547108

Özdemir, B.C., T. Pentcheva-Hoang, J.L. Carstens, X. Zheng, C.C. Wu, T.R Simpson, H. Laklai, H. Sugimoto, C. Kahlert, S.V. Novitskiy, et al. 2014. Depletion of carcinoma-associated fibroblasts and fibrosis induces immunosuppression and accelerates pancreas cancer with reduced survival Cancer Cell. 25:719-734. http://dx.doi.org/10.1016/j.ccr.2014.04.005

Paget, S. 1889. The distribution of secondary growths in cancer of the breast. Lancet.133:571-573.http://dx.doi.org/10.1016/S0140-6736(00)49915-0

Park, C.C., H. Zhang, M. Pallavicini, J.W. Gray, F. Baehner, C.J. Park, and M.J. Bissell. 2006. $\beta 1$ integrin inhibitory antibody induces apoptosis of breast cancer cells, inhibits growth, and distinguishes malignant from normal phenotype in three dimensional cultures and in vivo. Cancer Res. 66:1526-1535. http://dx.doi.org/10.1158/0008-5472.CAN-05-3071

Park, C.C., H.J. Zhang, E.S.Yao, C.J. Park, and M.J. Bissell. 2008. $\beta 1$ integrin inhibition dramatically enhances radiotherapy efficacy in human breast cancer xenografts. Cancer Res. 68:4398-4405.http://dx.doi.org/10.1158/ 0008-5472.CAN-07-6390

Patocs, A., L. Zhang, Y. Xu, F. Weber, T. Caldes, G.L. Mutter, P. Platzer, and C. Eng. 2007. Breast-cancer stromal cells with TP53 mutations and nodal metastases. N. Engl. J. Med. 357:2543-2551. http://dx.doi.org/ 10.1056/NEJMoa071825

Paunescu, V., F.M. Bojin, C.A. Tatu, O.I. Gavriliuc, A. Rosca, A.T. Gruia, G. Tanasie, C. Bunu, D. Crisnic, M. Gherghiceanu, et al. 2011. Tumour-associated fibroblasts and mesenchymal stem cells: more similarities than differences. J. Cell. Mol. Med. 15:635-646. http:// dx.doi.org/10.1111/j.1582-4934.2010.01044.x
Pavlides, S., D. Whitaker-Menezes, R. Castello-Cros, N. Flomenberg, A.K. Witkiewicz, P.G. Frank, M.C. Casimiro, C. Wang, P. Fortina, S. Addya, et al. 2009. The reverse Warburg effect: aerobic glycolysis in cancer associated fibroblasts and the tumor stroma. Cell Cycle. 8:39844001. http://dx.doi.org/10.4161/cc.8.23.10238

Peek, R.M. Jr., and J.E. Crabtree. 2006. Helicobacter infection and gastric neoplasia. J. Pathol. 208:233-248. http://dx.doi.org/10.1002/path.1868

Peruzzi, B., and D.P. Bottaro. 2006. Targeting the c-Met signaling pathway in cancer. Clin. Cancer Res. 12:3657-3660. http://dx.doi.org/10.1158/ 1078-0432.CCR-06-0818

Pickup, M., S. Novitskiy, and H.L. Moses. 2013a. The roles of TGF $\beta$ in the tumour microenvironment. Nat. Rev. Cancer. 13:788-799. http:// dx.doi.org/10.1038/nrc3603

Pickup, M.W., H. Laklai, I. Acerbi, P. Owens, A.E. Gorska, A. Chytil, M. Aakre, V.M. Weaver, and H.L. Moses. 2013b. Stromally derived lysyl oxidase promotes metastasis of transforming growth factor- $\beta$-deficient mouse mammary carcinomas. Cancer Res. 73:5336-5346. http://dx.doi .org/10.1158/0008-5472.CAN-13-0012

Pietras, K., and A. Ostman. 2010. Hallmarks of cancer: interactions with the tumorstroma. Exp. Cell Res.316:1324-1331.http://dx.doi.org/10.1016/ j.yexcr.2010.02.045

Pietras, K., J. Pahler, G. Bergers, and D. Hanahan. 2008. Functions of paracrine PDGF signaling in the proangiogenic tumor stroma revealed by pharmacological targeting. PLoS Med. 5:e19. http://dx.doi.org/ 10.1371/journal.pmed.0050019

Pikarsky, E., R.M. Porat, I. Stein, R. Abramovitch, S. Amit, S. Kasem, E. Gutkovich-Pyest, S. Urieli-Shoval, E. Galun, and Y. Ben-Neriah. 2004. $\mathrm{NF}-\mathrm{\kappa B}$ functions as a tumour promoter in inflammation-associated cancer. Nature. 431:461-466. http://dx.doi.org/10.1038/nature02924

Polito, A., and R. Reynolds. 2005. NG2-expressing cells as oligodendrocyte progenitors in the normal and demyelinated adult central nervous system.J.Anat. 207:707-716.http://dx.doi.org/10.1111/j.14697580.2005.00454.x

Poulsom, R., M. Pignatelli, W.G. Stetler-Stevenson, L.A. Liotta, P.A. Wright, R.E. Jeffery, J.M. Longcroft, L. Rogers, and G.W. Stamp. 1992. Stromal expression of $72 \mathrm{kda}$ type IV collagenase (MMP-2) and TIMP-2 mRNAs in colorectal neoplasia. Am. J. Pathol. 141:389-396.

Provenzano, P.P., C. Cuevas, A.E. Chang, V.K. Goel, D.D. Von Hoff, and S.R. Hingorani. 2012. Enzymatic targeting of the stroma ablates physical barriers to treatment of pancreatic ductal adenocarcinoma. Cancer Cell. 21:418-429. http://dx.doi.org/10.1016/j.ccr.2012.01.007

Qiu, W., M. Hu, A. Sridhar, K. Opeskin, S. Fox, M. Shipitsin, M. Trivett, E.R. Thompson, M. Ramakrishna, K.L. Gorringe, et al. 2008. No evidence of clonal somatic genetic alterations in cancer-associated fibroblasts from human breast and ovarian carcinomas. Nat. Genet. 40:650-655. http://dx.doi.org/10.1038/ng.117

Qu, C.F., E.Y. Song, Y. Li, S.M. Rizvi, C. Raja, R. Smith, A. Morgenstern, C. Apostolidis, and B.J. Allen. 2005. Pre-clinical study of 213Bi labeled PAI2 for the control of micrometastatic pancreatic cancer. Clin. Exp. Metastasis. 22:575-586. http://dx.doi.org/10.1007/ s10585-005-5788-9

Quante, M., S.P. Tu, H. Tomita, T. Gonda, S.S. Wang, S. Takashi, G.H. Baik, W. Shibata, B. Diprete, K.S. Betz, et al. 2011. Bone marrowderived myofibroblasts contribute to the mesenchymal stem cell niche and promote tumor growth. Cancer Cell. 19:257-272. http://dx.doi .org/10.1016/j.ccr.2011.01.020

Räsänen, K., and A.Vaheri. 2010. Activation of fibroblasts in cancer stroma. Exp. Cell Res. 316:2713-2722. http://dx.doi.org/10.1016/j.yexcr.2010.04.032

Reardon, D.A., K.L. Fink, T. Mikkelsen, T.F. Cloughesy, A. O'Neill, S. Plotkin, M. Glantz, P. Ravin, J.J. Raizer, K.M. Rich, et al. 2008. Randomized phase II study of cilengitide, an integrin-targeting arginine-glycineaspartic acid peptide, in recurrent glioblastoma multiforme. J. Clin. Oncol. 26:5610-5617. http://dx.doi.org/10.1200/JCO.2008.16.7510

Rhim, A.D., P.E. Oberstein, D.H.Thomas, E.T. Mirek, C.F. Palermo, S.A. Sastra, E.N. Dekleva, T. Saunders, C.P. Becerra, I.W. Tattersall, et al. 2014. Stromal elements act to restrain, rather than support, pancreatic ductal adenocarcinoma. Cancer Cell. 25:735-747. http://dx.doi.org/10.1016/j.ccr.2014.04.021

Roberts, E.W., A. Deonarine, J.O. Jones, A.E. Denton, C. Feig, S.K. Lyons, M. Espeli, M. Kraman, B. McKenna, R.J. Wells, et al. 2013. Depletion 
of stromal cells expressing fibroblast activation protein- $\alpha$ from skeletal muscle and bone marrow results in cachexia and anemia. J. Exp. Med. 210:1137-1151. http://dx.doi.org/10.1084/jem.20122344

Rønnov-Jessen, L., and O.W. Petersen. 1993. Induction of $\alpha$-smooth muscle actin by transforming growth factor- $\beta 1$ in quiescent human breast gland fibroblasts. Implications for myofibroblast generation in breast neoplasia. Lab. Invest. 68:696-707.

Rønnov-Jessen, L., and O.W. Petersen. 1996. A function for filamentous $\alpha$-smooth muscle actin: retardation of motility in fibroblasts. J. Cell Biol. 134:67-80. http://dx.doi.org/10.1083/jcb.134.1.67

Royal, R.E., C. Levy, K. Turner, A. Mathur, M. Hughes, U.S. Kammula, R.M. Sherry, S.L. Topalian, J.C. Yang, I. Lowy, and S.A. Rosenberg. 2010. Phase 2 trial of single agent Ipilimumab (anti-CTLA-4) for locally advanced or metastatic pancreatic adenocarcinoma. J. Immunother. 33:828-833. http://dx.doi.org/10.1097/CJI.0b013e3181eec14c

Saadi,A.,N.B.Shannon,P.Lao-Sirieix,M.O'Donovan,E.Walker,N.J.Clemons, J.S. Hardwick, C. Zhang, M. Das, V. Save, et al. 2010. Stromal genes discriminate preinvasive from invasive disease, predict outcome, and highlight inflammatory pathways in digestive cancers. Proc. Natl. Acad. Sci. USA. 107:2177-2182. http://dx.doi.org/10.1073/pnas.0909797107

Sakurai, T., M. Kudo, N. Fukuta, T. Nakatani, M. Kimura, A.M. Park, and H. Munakata. 2011. Involvement of angiotensin II and reactive oxygen species in pancreatic fibrosis. Pancreatology. 11:7-13. http://dx.doi.org/ 10.1159/000323478

Santos, A.M., J. Jung, N. Aziz, J.L. Kissil, and E. Puré. 2009. Targeting fibroblast activation protein inhibits tumor stromagenesis and growth in mice. J. Clin. Invest. 119:3613-3625. http://dx.doi.org/10.1172/JCI38988

Sanz-Moreno, V., C. Gaggioli, M. Yeo, J. Albrengues, F. Wallberg, A. Viros, S. Hooper, R. Mitter, C.C. Féral, M. Cook, et al. 2011. ROCK and JAK1 signaling cooperate to control actomyosin contractility in tumor cells and stroma. Cancer Cell. 20:229-245. http://dx.doi .org/10.1016/j.ccr.2011.06.018

Sato, N., N. Maehara, and M. Goggins. 2004. Gene expression profiling of tumor-stromal interactions between pancreatic cancer cells and stromal fibroblasts. Cancer Res. 64:6950-6956. http://dx.doi.org/10.1158/00085472.CAN-04-0677

Scanlan, M.J., B.K. Raj, B. Calvo, P. Garin-Chesa, M.P. Sanz-Moncasi, J.H. Healey, L.J. Old, and W.J. Rettig. 1994. Molecular cloning of fibroblast activation protein alpha, a member of the serine protease family selectively expressed in stromal fibroblasts of epithelial cancers. Proc. Natl. Acad. Sci. USA. 91:5657-5661. http://dx.doi.org/10.1073/pnas.91.12.5657

Scott,A.M., G.Wiseman, S. Welt, A.Adjei, F.T. Lee,W. Hopkins, C.R. Divgi, L.H. Hanson, P. Mitchell, D.N. Gansen, et al. 2003. A Phase I doseescalation study of sibrotuzumab in patients with advanced or metastatic fibroblast activation protein-positive cancer. Clin. Cancer Res. 9: 1639-1647.

Serini, G., M.L. Bochaton-Piallat, P. Ropraz, A. Geinoz, L. Borsi, L. Zardi, and G. Gabbiani. 1998. The fibronectin domain ED-A is crucial for myofibroblastic phenotype induction by transforming growth factor- $\beta 1$. J. Cell Biol. 142:873-881. http://dx.doi.org/10.1083/jcb.142.3.873

Sethi, T., R.C. Rintoul, S.M. Moore, A.C. MacKinnon, D. Salter, C. Choo, E.R. Chilvers, I. Dransfield, S.C. Donnelly, R. Strieter, and C. Haslett. 1999. Extracellular matrix proteins protect small cell lung cancer cells against apoptosis: a mechanism for small cell lung cancer growth and drug resistance in vivo. Nat. Med. 5:662-668. http://dx.doi.org/10.1038/9511

Shao, Z.M., M. Nguyen, and S.H. Barsky. 2000. Human breast carcinoma desmoplasia is PDGF initiated. Oncogene. 19:4337-4345. http://dx .doi.org/10.1038/sj.onc. 1203785

Sherman-Baust, C.A., A.T. Weeraratna, L.B. Rangel, E.S. Pizer, K.R. Cho, D.R. Schwartz, T. Shock, and P.J. Morin. 2003. Remodeling of the extracellular matrix through overexpression of collagen VI contributes to cisplatin resistance in ovarian cancer cells. Cancer Cell. 3:377-386. http://dx.doi.org/10.1016/S1535-6108(03)00058-8

Shimoda, M., K.T. Mellody, and A. Orimo. 2010. Carcinoma-associated fibroblasts are a rate-limiting determinant for tumour progression. Semin. Cell Dev. Biol. 21:19-25. http://dx.doi.org/10.1016/j.semcdb 2009.10.002

Singh, S., S.R. Ross, M. Acena, D.A. Rowley, and H. Schreiber. 1992. Stroma is critical for preventing or permitting immunological destruction of antigenic cancer cells. J. Exp. Med. 175:139-146. http://dx.doi.org/ 10.1084/jem.175.1.139

Singh, S., S.K. Srivastava, A. Bhardwaj, L.B. Owen, and A.P. Singh. 2010. CXCL12-CXCR 4 signalling axis confers gemcitabine resistance to pancreatic cancer cells: a novel target for therapy. Br. J. Cancer. 103:16711679. http://dx.doi.org/10.1038/sj.bjc.6605968

Smith, N.R., D. Baker, M. Farren, A. Pommier, R. Swann, X. Wang, S. Mistry, K. McDaid, J. Kendrew, C. Womack, et al. 2013. Tumor stromal architecture can define the intrinsic tumor response to VEGFtargeted therapy. Clin. Cancer Res. 19:6943-6956. http://dx.doi.org/10 .1158/1078-0432.CCR-13-1637

Sosman, J.A., K.B. Kim, L. Schuchter, R. Gonzalez, A.C. Pavlick, J.S. Weber, G.A. McArthur, T.E. Hutson, S.J. Moschos, K.T. Flaherty, et al. 2012. Survival in BRAF V600-mutant advanced melanoma treated with vemurafenib. N. Engl. J. Med. 366:707-714. http://dx.doi.org/10.1056/ NEJMoa1112302

Sounni, N.E., K. Dehne, L. van Kempen, M. Egeblad, N.I. Affara, I. Cuevas, J. Wiesen, S. Junankar, L. Korets, J. Lee, et al. 2010. Stromal regulation of vessel stability by MMP14 and TGF $\beta$. Dis. Model. Mech. 3:317-332. http://dx.doi.org/10.1242/dmm.003863

Sternlicht, M.D., A. Lochter, C.J. Sympson, B. Huey, J.P. Rougier, J.W. Gray, D. Pinkel, M.J. Bissell, and Z. Werb. 1999. The stromal proteinase MMP3/stromelysin-1 promotes mammary carcinogenesis. Cell. 98:137-146. http://dx.doi.org/10.1016/S0092-8674(00)81009-0

Stetler-Stevenson, W.G., S. Aznavoorian, and L.A. Liotta. 1993. Tumor cell interactions with the extracellular matrix during invasion and metastasis. Annu. Rev. Cell Biol. 9:541-573. http://dx.doi.org/10.1146/annurev .cb.09.110193.002545

Stoker, M.G., M. Shearer, and C. O'Neill. 1966. Growth inhibition of polyoma-transformed cells by contact with static normal fibroblasts. $J$. Cell Sci. 1:297-310.

Straussman, R., T. Morikawa, K. Shee, M. Barzily-Rokni, Z.R. Qian, J. Du, A. Davis, M.M. Mongare, J. Gould, D.T. Frederick, et al. 2012. Tumour micro-environment elicits innate resistance to RAF inhibitors through HGF secretion. Nature. 487:500-504. http://dx.doi.org/10.1038/ nature11183

Strutz, F., H. Okada, C.W. Lo, T. Danoff, R.L. Carone, J.E. Tomaszewski, and E.G. Neilson. 1995. Identification and characterization of a fibroblast marker: FSP1. J. Cell Biol. 130:393-405. http://dx.doi.org/10.1083/ jcb.130.2.393

Strutz, F., M. Zeisberg, B. Hemmerlein, B. Sattler, K. Hummel, V. Becker, and G.A. Müller. 2000. Basic fibroblast growth factor expression is increased in human renal fibrogenesis and may mediate autocrine fibroblast proliferation. Kidney Int. 57:1521-1538. http://dx.doi.org/10.1046/ j.1523-1755.2000.00997.x

Sugimoto, H.,T.M. Mundel, M.W. Kieran, and R. Kalluri. 2006. Identification of fibroblast heterogeneity in the tumor microenvironment. Cancer Biol. Ther. 5:1640-1646. http://dx.doi.org/10.4161/cbt.5.12.3354

Sun, Y., J. Campisi, C. Higano, T.M. Beer, P. Porter, I. Coleman, L. True, and P.S. Nelson. 2012. Treatment-induced damage to the tumor microenvironment promotes prostate cancer therapy resistance through WNT16B. Nat. Med. 18:1359-1368. http://dx.doi.org/10.1038/nm.2890

Teicher, B.A., T.S. Herman, S.A. Holden, Y.Y. Wang, M.R. Pfeffer, J.W. Crawford, and E. Frei III. 1990. Tumor resistance to alkylating agents conferred by mechanisms operative only in vivo. Science. 247:14571461. http://dx.doi.org/10.1126/science. 2108497

Thayer, S.P., M.P. di Magliano, P.W. Heiser, C.M. Nielsen, D.J. Roberts, G.Y. Lauwers,Y.P. Qi, S. Gysin, C. Fernández-del Castillo,V.Yajnik, et al. 2003. Hedgehog is an early and late mediator of pancreatic cancer tumorigenesis. Nature. 425:851-856. http://dx.doi.org/10.1038/nature02009

Tomasek, J.J., G. Gabbiani, B. Hinz, C. Chaponnier, and R.A. Brown. 2002. Myofibroblasts and mechano-regulation of connective tissue remodelling. Nat. Rev. Mol. Cell Biol. 3:349-363. http://dx.doi.org/10.1038/nrm809

Torres, S., R.A. Bartolomé, M. Mendes, R. Barderas, M.J. Fernandez-Aceñero, A. Peláez-García, C. Peña, M. Lopez-Lucendo, R. Villar-Vázquez, A.G. de Herreros, et al. 2013. Proteome profiling of cancer-associated fibroblasts identifies novel proinflammatory signatures and prognostic markers for colorectal cancer. Clin. Cancer Res. 19:6006-6019. http:// dx.doi.org/10.1158/1078-0432.CCR-13-1130 
Toullec, A., D. Gerald, G. Despouy, B. Bourachot, M. Cardon, S. Lefort, M. Richardson, G. Rigaill, M.C. Parrini, C. Lucchesi, et al. 2010. Oxidative stress promotes myofibroblast differentiation and tumour spreading. EMBO Mol. Med. 2:211-230. http://dx.doi.org/10.1002/emmm.201000073

Trimboli, A.J., C.Z. Cantemir-Stone, F. Li, J.A. Wallace, A. Merchant, N. Creasap, J.C. Thompson, E. Caserta, H. Wang, J.L. Chong, et al. 2009. Pten in stromal fibroblasts suppresses mammary epithelial tumours. Nature. 461:1084-1091. http://dx.doi.org/10.1038/nature08486

Tsujino, T., I. Seshimo, H. Yamamoto, C.Y. Ngan, K. Ezumi, I. Takemasa, M. Ikeda, M. Sekimoto, N. Matsuura, and M. Monden. 2007. Stromal myofibroblasts predict disease recurrence for colorectal cancer. Clin. Cancer Res. 13:2082-2090. http://dx.doi.org/10.1158/1078-0432.CCR-06-2191

Vermeulen, L., F. De Sousa E Melo, M. van der Heijden, K. Cameron, J.H. de Jong, T. Borovski, J.B. Tuynman, M. Todaro, C. Merz, H. Rodermond, et al. 2010. Wnt activity defines colon cancer stem cells and is regulated by the microenvironment. Nat. Cell Biol. 12:468-476. http://dx.doi.org/10.1038/ncb2048

Vicent, S., L.C. Sayles, D. Vaka, P. Khatri, O. Gevaert, R. Chen, Y. Zheng, A.K. Gillespie, N. Clarke, Y. Xu, et al. 2012. Cross-species functional analysis of cancer-associated fibroblasts identifies a critical role for CLCF1 and IL-6 in non-small cell lung cancer in vivo. Cancer Res. 72:5744-5756. http://dx.doi.org/10.1158/0008-5472.CAN-12-1097

Von Hoff, D.D., R.K. Ramanathan, M.J. Borad, D.A. Laheru, L.S. Smith, T.E. Wood, R.L. Korn, N. Desai, V. Trieu, J.L. Iglesias, et al. 2011. Gemcitabine plus nab-paclitaxel is an active regimen in patients with advanced pancreatic cancer: a phase I/II trial. J. Clin. Oncol. 29:45484554. http://dx.doi.org/10.1200/JCO.2011.36.5742

Vosseler, S., W. Lederle, K. Airola, E. Obermueller, N.E. Fusenig, and M.M. Mueller. 2009. Distinct progression-associated expression of tumor and stromal MMPs in $\mathrm{HaCaT}$ skin SCCs correlates with onset of invasion. Int. J. Cancer. 125:2296-2306. http://dx.doi.org/10.1002/ijc.24589

Walter, K., N. Omura, S.M. Hong, M. Griffith, and M. Goggins. 2008. Pancreatic cancer associated fibroblasts display normal allelotypes. Cancer Biol. Ther. 7:882-888. http://dx.doi.org/10.4161/cbt.7.6.5869

Wang, X.M., D.M. Yu, G.W. McCaughan, and M.D. Gorrell. 2005. Fibroblast activation protein increases apoptosis, cell adhesion, and migration by the LX-2 human stellate cell line. Hepatology. 42:935-945. http://dx.doi.org/10.1002/hep.20853

Wang, Z., Q. Ma, Q. Liu, H. Yu, L. Zhao, S. Shen, and J. Yao. 2008. Blockade of SDF-1/CXCR4 signalling inhibits pancreatic cancer progression in vitro via inactivation of canonical Wnt pathway. Br. J. Cancer. 99:1695-1703. http://dx.doi.org/10.1038/sj.bjc.6604745

Wang, W., Q. Li, T. Yamada, K. Matsumoto, I. Matsumoto, M. Oda, G. Watanabe, Y. Kayano, Y. Nishioka, S. Sone, and S. Yano. 2009a. Crosstalk to stromal fibroblasts induces resistance of lung cancer to epidermal growth factor receptor tyrosine kinase inhibitors. Clin. Cancer Res. 15:6630-6638. http://dx.doi.org/10.1158/1078-0432.CCR-091001

Wang, Z., Y. Li, D. Kong, S. Banerjee, A. Ahmad, A.S. Azmi, S. Ali, J.L. Abbruzzese, G.E. Gallick, and F.H. Sarkar. 2009b. Acquisition of epithelial-mesenchymal transition phenotype of gemcitabine-resistant pancreatic cancer cells is linked with activation of the notch signaling pathway. Cancer Res. 69:2400-2407. http://dx.doi.org/10.1158/00085472.CAN-08-4312

Wang, J., G. Ying, J. Wang, Y. Jung, J. Lu, J. Zhu, K.J. Pienta, and R.S. Taichman. 2010. Characterization of phosphoglycerate kinase-1 expression of stromal cells derived from tumor microenvironment in prostate cancer progression. Cancer Res. 70:471-480. http://dx.doi .org/10.1158/0008-5472.CAN-09-2863

Webber, J., R. Steadman, M.D. Mason, Z. Tabi, and A. Clayton. 2010. Cancer exosomes trigger fibroblast to myofibroblast differentiation. Cancer Res. 70:9621-9630. http://dx.doi.org/10.1158/0008-5472.CAN-10-1722

Weissmueller, S., E. Manchado, M. Saborowski, J.P. Morris IV, E. Wagenblast, C.A. Davis, S.H. Moon, N.T. Pfister, D.F. Tschaharganeh,
T. Kitzing, et al. 2014. Mutant p53 drives pancreatic cancer metastasis through cell-autonomous PDGF receptor $\beta$ signaling. Cell. 157:382394. http://dx.doi.org/10.1016/j.cell.2014.01.066

Wen, J., K. Matsumoto, N. Taniura, D. Tomioka, and T. Nakamura. 2004. Hepatic gene expression of NK4, an HGF-antagonist/angiogenesis inhibitor, suppresses liver metastasis and invasive growth of colon cancer in mice. Cancer Gene Ther. 11:419-430. http://dx.doi.org/10.1038/sj.cgt.7700705

Wendling, O., J.M. Bornert, P. Chambon, and D. Metzger. 2009. Efficient temporally-controlled targeted mutagenesis in smooth muscle cells of the adult mouse. Genesis. 47:14-18. http://dx.doi.org/10.1002/dvg.20448

Williams, C.S., M. Tsujii, J. Reese, S.K. Dey, and R.N. DuBois. 2000 Host cyclooxygenase-2 modulates carcinoma growth. J. Clin. Invest. 105:1589-1594. http://dx.doi.org/10.1172/JCI9621

Wilson, T.R., J. Fridlyand, Y. Yan, E. Penuel, L. Burton, E. Chan, J. Peng, E. Lin, Y. Wang, J. Sosman, et al. 2012. Widespread potential for growth-factor-driven resistance to anticancer kinase inhibitors. Nature. 487:505-509. http://dx.doi.org/10.1038/nature11249

Witkiewicz, A.K., D. Whitaker-Menezes, A. Dasgupta, N.J. Philp, Z. Lin, R. Gandara, S. Sneddon, U.E. Martinez-Outschoorn, F. Sotgia, and M.P. Lisanti. 2012. Using the "reverse Warburg effect" to identify high-risk breast cancer patients: stromal MCT4 predicts poor clinical outcome in triple-negative breast cancers. Cell Cycle. 11:1108-1117. http://dx.doi.org/10.4161/cc.11.6.19530

Xing, F., J. Saidou, and K. Watabe. 2010. Cancer associated fibroblasts (CAFs) in tumor microenvironment. Front Biosci (Landmark Ed). 15: 166-179. http://dx.doi.org/10.2741/3613

Xu, Z., A. Vonlaufen, P.A. Phillips, E. Fiala-Beer, X. Zhang, L. Yang, A.V. Biankin, D. Goldstein, R.C. Pirola, J.S. Wilson, and M.V. Apte. 2010. Role of pancreatic stellate cells in pancreatic cancer metastasis. Am. J. Pathol. 177:2585-2596. http://dx.doi.org/10.2353/ajpath.2010.090899

Yang, F., J.A. Tuxhorn, S.J. Ressler, S.J. McAlhany, T.D. Dang, and D.R. Rowley. 2005. Stromal expression of connective tissue growth factor promotes angiogenesis and prostate cancer tumorigenesis. Cancer Res. 65:8887-8895. http://dx.doi.org/10.1158/0008-5472.CAN-05-1702

Yang, G., D.G. Rosen, Z. Zhang, R.C. Bast Jr., G.B. Mills, J.A. Colacino, I. Mercado-Uribe, and J. Liu. 2006. The chemokine growth-regulated oncogene 1 (Gro-1) links RAS signaling to the senescence of stromal fibroblasts and ovarian tumorigenesis. Proc. Natl. Acad. Sci. USA. 103:16472-16477. http://dx.doi.org/10.1073/pnas.0605752103

Yauch, R.L., S.E. Gould, S.J. Scales, T. Tang, H. Tian, C.P. Ahn, D. Marshall, L. Fu, T. Januario, D. Kallop, et al. 2008. A paracrine requirement for hedgehog signalling in cancer. Nature. 455:406-410. http:// dx.doi.org/10.1038/nature 07275

Yin, C., K.J. Evason, K. Asahina, and D.Y. Stainier. 2013. Hepatic stellate cells in liver development, regeneration, and cancer. J. Clin. Invest. 123:1902-1910. http://dx.doi.org/10.1172/JCI66369

Zeisberg, E.M., S. Potenta, L. Xie, M. Zeisberg, and R. Kalluri. 2007. Discovery of endothelial to mesenchymal transition as a source for carcinoma-associated fibroblasts. Cancer Res. 67:10123-10128. http:// dx.doi.org/10.1158/0008-5472.CAN-07-3127

Zhang, J., L. Chen, X. Liu, T. Kammertoens, T. Blankenstein, and Z. Qin. 2013a. Fibroblast-specific protein 1/S100A4-positive cells prevent carcinoma through collagen production and encapsulation of carcinogens. Cancer Res. 73:2770-2781. http://dx.doi.org/10.1158/0008-5472 .CAN-12-3022

Zhang, X.H., X. Jin, S. Malladi, Y. Zou, Y.H. Wen, E. Brogi, M. Smid, J.A. Foekens, and J. Massagué. 2013b. Selection of bone metastasis seeds by mesenchymal signals in the primary tumor stroma. Cell. 154:10601073. http://dx.doi.org/10.1016/j.cell.2013.07.036

Zigrino, P., I. Kuhn, T. Bäuerle, J. Zamek, J.W. Fox, S. Neumann, A. Licht, M. Schorpp-Kistner, P. Angel, and C. Mauch. 2009. Stromal expression of MMP-13 is required for melanoma invasion and metastasis. J. Invest. Dermatol. 129:2686-2693. http://dx.doi.org/10.1038/jid .2009 .130 